\title{
Polarization Weather Radar Development from 1970-1995: Personal Reflections
}

\author{
Viswanathan Bringi ${ }^{1, *}$ and Dusan Zrnic ${ }^{2}$ \\ 1 Department of Electrical and Computer Engineering, Colorado State University, Fort Collins, CO 80523, USA \\ 2 National Severe Storms Laboratory/NOAA, Norman, OK 73072, USA; dusan.zrnic@noaa.gov \\ * Correspondence: bringi@colostate.edu
}

Received: 16 October 2019; Accepted: 13 November 2019; Published: 15 November 2019

\begin{abstract}
The modern era of polarimetric radar begins with radiowave propagation research starting in the early 1970s with applications to measurement and modeling of wave attenuation in rain and depolarization due to ice particles along satellite-earth links. While there is a rich history of radar in meteorology after World War II, the impetus provided by radiowave propagation requirements led to high-quality antennas and feeds. Our journey starts by describing the key institutions and personnel responsible for development of weather radar polarimetry. The early period was dominated by circularly polarized radars for propagation research and at $S$ band (frequency near $3 \mathrm{GHz}$ ) for hail detection. By the mid to late 70s, a paradigm shift occurred which led to the dominance of linear polarizations with applications to slant path attenuation prediction as well as estimation of rain rates and inferences of precipitation physics. The period from the early 1980s to 1995 can be considered as the "golden" period of rapid research that brought in meteorologists, cloud physicists, and hydrologists. This article describes the evolution of this technology from the vantage point of the authors. Their personal reflections and "behind the scenes" descriptions offer a glimpse into the inner workings at several key institutions which cannot be found elsewhere.
\end{abstract}

Keywords: radar; dual-polarization; precipitation

\section{Introduction}

The electromagnetic wave is defined by amplitude, frequency, and polarization state. These properties change because of interaction with precipitation, and relating these changes to particle microphysical states including Doppler velocity and spectrum width is the main purpose of dual-polarized Doppler weather radar. The electromagnetic theory rooted in Maxwell's equations has played a central role in the development and application of polarimetric weather radar. There is a rich history of radar in meteorology since World War II for which we defer to the Battan Memorial Conference Proceedings published in Radar in Meteorology [1] edited by the late David Atlas. Our objective in this article is much less ambitious in that we describe the early years of dual-polarization research in meteorology and related radiowave propagation starting from the mid-1970s to about the early 1990s. In the mid-70s the number of papers on dual-polarized radar presented in the American Meteorological Society (AMS) Radar Meteorology conferences was $<5$ while by the mid-90s this number reached 50 . Thus, this period was chosen, albeit subjectively, as it marks the beginning of the modern era of radar polarimetry to the point beyond which the accelerated pace of research and applications probably reached its peak but not mature enough to be adopted by the operational weather services. The authors were closely involved with, and had intimate knowledge of, the principal players and institutions active during this period so this article reflects their opinions from that vantage point. Also, much of the research during this period is described in detail in several books [2,3]. For convenience a table of abbreviations is given at the end of this article. 
The modern era of polarimetric radar began in the early 1970s driven largely by the radiowave propagation scientists who were characterizing attenuation and depolarization of electromagnetic (EM) waves due to rain and ice particles along satellite-earth links at microwave and millimeter wavelengths. Related advances in accurate dual-polarization antenna feed design, precise reflector manufacturing methods, and microwave circuits were driven by stringent earth station antenna requirements on sidelobes and on-axis cross-polarization levels. This also contributed significantly to weather radar polarimetry. Much of this early work involved researchers with strong backgrounds in electromagnetic scattering theory, microwave engineering, and signal processing. Their work led to a wider recognition of the intrinsic value of polarimetry in radar meteorology and in the next two decades inspired strong contributions by meteorologists and nonspecialists alike. This was aided by the ready availability of numerical scattering software tools and reliable and high quality data from polarimetric radars, as well as advances in cloud and precipitation physics. Currently, the operational deployment of polarimetric Doppler weather radars by nearly all weather service agencies world-wide has led to research advancements scarcely foreseen by the early pioneers. It continues to grow with advances in numerical microphysical models of precipitation growth and evolution that predict the physical properties needed by advanced scattering models.

The first workshop on dual-polarization radar lead by Metcalf and Humphries [4] was held the day before the AMS Radar Meteorology Conference in Miami Beach in 1980 where all of eight conference papers on dual-polarization topics were presented. The workshop had 21 attendees, mainly from the US, Canada, and the UK. The goal was to assess the meteorological applications of dual-polarization and system design considerations as well as experimental procedures used at that time. Short presentations were made based on the experiences at the relevant institutions such as New Mexico Tech, Rutherford Appleton Laboratory, National Research Council of Canada, Alberta Research Council, and NOAA-Wave Propagation Laboratory. It was recognized that the different institutions were proceeding along their own lines of research but there was strong support for a coherent polarization agile dual-receiver system. Polarization agility is defined here as the capability of the radar to transmit polarization states that alternate between two orthogonal states (e.g., horizontal and vertical) from pulse-to-pulse ("fast"-switched) with typically only a single receiver that receives the copolar signal. Polarization diversity refers to transmitting a specified polarization state and receiving the copol and cross-pol signals using two receivers.

To make this article tractable, we describe the seminal or landmark papers that provided ideas and impetus for research sometimes occurring decades later. In addition to the role of EM theory we include processing and statistical analysis of signals. We start with the work by McCormick and Hendry at the National Research Council of Canada in the early 1970s. They were able to make more accurate dual-pol radar measurements than possible hitherto, with high performance antennas, feeds, and polarizer networks using circular polarization basis. In parallel they guided the upgrade of the Alberta Research Council S-band radar to circular polarization for hail detection. The next sections describe the nature of how some of the early work using horizontal-vertical polarization basis developed at the institutions and laboratories that the authors worked in or had close associations with, giving a personal historical and "behind the scenes" look that is often left out in the archival journal articles but is useful to record. Any important work we may have missed or overlooked is entirely unintentional.

\section{Brief Overview of Electromagnetics in Dual-Polarization Radar and Related Topics}

The radar range equation for single linear polarization is well known to the radar meteorological community but less well known is the voltage form of this equation for dual-polarization radars. Our notation is bold face for vectors and bold face italic with underbar for matrices. We use mixed vector-matrix equations and exclude constants for simplicity. The voltage equation is given as $\mathrm{V}=\mathbf{h} \bullet \mathrm{E}_{\mathbf{s}}$ where $\mathbf{h}$ describes the effective antenna "height" defined as $\mathbf{h}=\lambda G^{1 / 2} \mathbf{e}_{\mathbf{h}}$ and $\mathbf{E}_{\mathbf{s}}$ is the backscattered wave from the particle [5]. The wavelength is $\lambda, G$ is the gain, and $\mathbf{e}_{\mathbf{h}}$ is the unit vector which describes 
the radiated polarization state. In general, $\mathbf{e}_{\mathbf{h}}$ could be elliptically polarized (described by the ellipticity angle $\tau$ and orientation angle $\Phi$ of the ellipse) but most common is the linear antenna polarization state (defined by convention when the antenna is radiating with $\tau=0$ and $\Phi=0,90^{\circ}$ corresponding to $\mathrm{H}$ and $\mathrm{V}$ polarizations, respectively). The $2 \times 2$ scattering matrix $\underline{S}$ describes the interaction between the wave incident on the particle and the wave that is scattered back, $\mathbf{E}_{\mathbf{s}}=\underline{S} \mathbf{E}_{\text {inc }}$ [6]. Thus, the voltage equation takes the bilinear form $\mathrm{V}=\mathbf{h} \bullet\left[\underline{S} \mathrm{E}_{\mathrm{inc}}\right]$ and the received power is $\left.\overline{\mid \mathrm{h}} \bullet\left[\underline{S} \mathrm{E}_{\mathrm{inc}}\right]\right|^{2}$ [7]. From the expression for the received power, the generalized form of the radar cross-section takes the more familiar form $\sigma\left(\mathbf{e}_{\mathbf{h}}, \mathbf{e}_{\text {inc }}\right)=4 \pi\left|\mathbf{e}_{\mathbf{h}} \bullet\left[\underline{S} \mathbf{e}_{\text {inc }}\right]\right|^{2}$ where the unit polarization vector for the antenna is $\mathbf{e}_{\mathbf{h}}$ and that of the incident wave is $\mathbf{e}_{\mathbf{i n c}}$. Note that the copolar radar cross-section is defined when $\mathbf{e}_{\mathbf{h}}=\mathbf{e}_{\mathbf{i n c}}$ whereas for cross-pol $\mathbf{e}_{\mathbf{h}}$ is orthogonal to $\mathbf{e}_{\mathbf{i n c}}$. From [2], for a sphere whose scattering matrix is for simplicity given by $S h h=S v v=1$, Shv $=0$, the $\sigma_{\mathrm{co}}=4 \pi\left(2 \cos ^{2} \tau_{\text {inc }}-1\right)^{2}$ and $\sigma_{\mathrm{cx}}=4 \pi\left(4 \cos ^{2} \tau_{\text {inc }} \sin ^{2} \tau_{\text {inc }}\right)$.

The voltage form of the radar range equation in the circular polarization $\left(\tau=45^{\circ}\right)$ basis was derived in [8]. From this, the elements of the $2 \times 2$ coherency matrix (two real power terms and one complex correlation) follow, the complex correlation being one of the central elements of their theory [8]. However, the coherency matrix is not complete for partially polarized backscatter as evidenced by the nine real terms of the Mueller matrix [9]. To achieve completeness, the $3 \times 3$ Hermitian covariance matrix is needed which has three real (power) terms and three complex correlation terms [10]. The early dual-pol radars $[11,12]$ were polarization agile but measured only two power terms $(\mathrm{HH}, \mathrm{VV})$ using a single receiver.

Matrosov [13], using a $35 \mathrm{GHz}$ radar, proposed transmitting a slightly elliptical polarized wave (ellipticity angle $\tau$ of $\left.40^{\circ}\right)$. For drizzle (spherical droplets) the elliptical depolarization ratio $\left(\sigma_{\mathrm{co}} / \sigma_{\mathrm{cx}}\right)$ or Elliptical Depolarization Ratio (EDR) turns to be $-14 \mathrm{~dB}$ independent of elevation angle and forms a reference against which to compare the elevation angle dependence of EDR for other types of ice crystals, e.g., branched planar dendrites or irregular graupel. RHI scans in horizontally homogeneous winter precipitation showed dramatic swings of $(8 \mathrm{~dB})$ in EDR for plate-like crystals with elevation angle from 0 to 90 whereas irregular graupel showed EDR about $1 \mathrm{~dB}$ higher than for drizzle with no elevation angle dependence.

Coherent propagation of dual-polarized EM waves in precipitation media was formulated in [14] in the form of a complex $2 \times 2$ transmission matrix $(T)$ which enters into the voltage form of the radar range equation as $\mathrm{V}=\mathbf{h} \bullet\left[T^{t} S T\right]$ where superscript $(\bar{t})$ is the matrix transpose. This complicates the separation of backscatter from propagation effects such as differential attenuation and differential phase shift which causes depolarization of the transmitted wave even at long wavelengths (S-band). In [15], McCormick and Hendry showed that when propagation effects dominate the signal returns then a complex plane plot of what they term as $W / W_{2}$ ( $W$ is the complex correlation and $W_{2}$ is the power in the main signal channel) as a function of increasing range can be used to measure differential attenuation and differential phase (as path averages over homogeneous sections). From these complex plane plots they were able to determine the anisotropy of the propagation medium and the first measurements in rain and snow were at $\mathrm{K}_{\mathrm{u}}$-band and later at X-band in [16], which, additionally, used "slow" switching between right-hand and left-hand circular polarizations. Some years later Hendry confided to one of the authors (V.N.B) that one personal highlight of their $\mathrm{K}_{\mathrm{u}}$-band measurements in snow was the recognition that the particles responsible for the circular depolarization ratio (i.e., the larger nonspherical aggregates with large variance of shapes) were different from those that contributed most to the differential propagation phase (i.e., horizontally oriented plate-like ice crystals). As described in the Canadian work, a principal conclusion was that raindrops form a highly oriented anisotropic propagation medium with symmetry axis near vertical. They also determined that differential phase shift due to oriented ice crystals aloft in thunderstorms could reveal changes that correlate with lightning discharges [17]. Later, using real-time displays of differential propagation phase shifts based on polarization agile $(\mathrm{H}, \mathrm{V})$-basis data, the aforementioned changes could be easily identified by rapid RHI scans through thunderstorm cores aloft. There the differential propagation phase would decrease with range as electrostatic fields oriented the crystals vertically. The lightning 
discharge that followed relaxed the crystals into horizontal orientation and the differential phase would start increasing with range [18,19]; the process repeated at regular intervals. One of the authors (V.N.B) witnessed this repetitive "charge" and "discharge" phenomena by observing real-time displays on the Colorado State University-University of Chicago and Illinois State Water Survey (CSU-CHILL) radar RHI scans with chief engineer David Brunkow and it was a thrilling moment to see electromagnetic theory at work in nature and to observe it so easily.

In collaboration with NRC Canada, an S-band circularly polarized radar funded by the Alberta Research Council was built for hail detection using a combination of reflectivity, circular depolarization ratio, and cross-correlation [20,21]. However, effects of the transmission matrix on circular polarization radar observables resulted in depolarization of the transmitted wave due to pure differential phase shift in heavier rain that made it difficult to separate the backscatter effects from the effects due to propagation, as modelled in [22]. It was not until a decade later when Anthony Holt and David Bebbington from the UK re-analyzed the Alberta Research Council (ARC) data and devised a method for "correcting" the differential propagation phase that enabled recovery of the "intrinsic" backscatter elements of the coherency matrix [23]. In a follow-up article [24], Holt gave a simpler derivation and, in addition, provided algorithms to retrieve differential propagation phase and differential reflectivity $\left(Z_{D R}\right)$. In [25] the ARC radar data were "corrected" and re-analyzed to show that combined use of reflectivity, $Z_{\mathrm{DR}}$ and to some extent the "degree of orientation" could identify hail and rain-hail mixtures.

It is noteworthy that the prototype and 13 preproduction units of the Weather Surveillance Radar 88 Doppler (WSR-88D) had circular polarization (WSR-88D is the US National Weather Service Doppler radar). However, unlike the Canadian radars, they were not configured to measure the full coherency matrix, but rather only one element (e.g., transmit right-hand circular (RHC) and coherently receive the "main" signal in the left-hand circular (LHC) port). This and other technical details of the future WSR-88D were confidential to protect the intellectual property of the bidding companies. Ista Zawadzki and Martin Hall were among the first ones to find out and they alerted researchers in the USA, including Dusan Zrnic (D.Z.). Differential propagation phase measurements in rain with the Cimarron dual-polarization radar (see Section 7) was reported in [26]. They proposed a relation between the specific differential phase $\left(\mathrm{K}_{\mathrm{DP}}\right)$ and rain rate. From this relation and the Marshal Palmer $\mathrm{R}(\mathrm{Z})$ relation, D.Z. quickly computed the differential phase along some radials of reflectivity. The results indicated that the differential propagation phase could easily reach $180^{\circ}$ in strong convective rain. The voltage in the intended LHC port can be simply expressed as $\mathrm{V}_{\mathrm{L}}=\cos \left(\mathrm{K}_{\mathrm{DP}} \bullet r\right)$ where $\mathrm{r}$ is the range to the resolution volume [2]. Since it is assumed that two-way differential propagation phase (defined as $2 \mathrm{~K}_{\mathrm{DP}} \bullet \mathrm{r}$ ) reaches $180^{\circ}$ or $\mathrm{K}_{\mathrm{DP}} \bullet$ r reaches $90^{\circ}$, the LHC port receives no signal whereas the returned signal would be terminated at the RHC port. Recognizing that this "artificial" loss in the return signal would be devastating, D.Z. wrote a memo about this loss to Dr. Vernon Derr, the director of the Environmental Research Laboratories (National Severe Storms Laboratory is one of these laboratories), who informed the National Weather Service (NWS). The transmit polarization was soon changed to linear horizontal. This issue raised awareness among the NWS personnel about the impact of radar polarimetry.

Meanwhile scientists from the National Center for Atmospheric Research (NCAR) (Rit Carbone) and Illinois State Water Survey (Gene Muller) lead by Thomas Seliga (Ohio State) approached the NWS with a request to include dual-polarization in the forthcoming Weather Surveillance Radar 1988 Doppler (WSR-88D) or Next Generation Weather Radar (NEXRAD). The NWS postponed the decision about dual-polarization but insisted in the procurement specifications that contractors furnish technical/conceptual details on how they would upgrade to dual-polarization in the future. Ultimately, Andrew Canada, the antenna subcontractor to the winner of the award, manufactured a dual-polarization feed with orthomode transducer (OMT) (their proprietary design) and measured the patterns at the two polarizations. Their feed-OMT was later installed on the NEXRAD antenna for proof-of-concept of the dual-polarization upgrade [27]. 
An important development occurred in 1990 when the CHILL (University of Chicago-Illinois State Water Survey) S-band radar was relocated to Colorado State University as a national facility funded by the National Science Foundation (NSF) for both education and research with close cooperation between the Departments of Atmospheric Science (Steven Rutledge) and Electrical Engineering (V.N.B, the lead author of this review; later joined by V. Chandrasekar). Under the leadership of the late Gene Mueller and engineer David Brunkow, the CSU-CHILL radar was continuously upgraded and in 1995 was configured with two transmitters (the second transmitter was a spare from the Norman radar at NSSL) and dual-receivers which allowed for a number of operating modes. In particular, the two transmitters could be "fired" either alternately or simultaneously (with equal power to approximate slant $45^{\circ}$ linear state), and receiving the $\mathrm{H}$ and $\mathrm{V}$ components of the backscattered field. Comparing polarimetric data from these two modes in rain and demonstrating their consistency [28] was an important initial result that assisted the proof-of-concept of the dual-pol upgrade alluded to above.

Calculations of the scattering matrix (both back and forward directions) for a single particle at low frequencies (Rayleigh scattering) and higher frequencies (non-Rayleigh scattering) is an important application of EM theory. It models the expected values of radar observables as functions of size, shape, orientation, and dielectric constant, as well as the incidence angle. The radar observables are obtained from averages of the covariance matrix elements (i.e., second order temporal moments) whereas the transmission matrix elements ensue from coherent integration of the forward scatter amplitudes [14]. Typical "bulk" assumptions are (1) particle size distributions based on gamma $p d f$, (2) equivalent spheroidal shapes with mean axis ratios either fixed or specified as a function of size, (3) Gaussian orientation distributions with mean and standard deviation fixed or dependent on tumbling/wobbling or degree of melting or riming, and (4) effective medium approximations for the dielectric constant of particles, e.g., low-density or mixed-phase.

Substantial literature exists for Rayleigh scattering, either analytical such as Gans' method for spheroids (as derived in [29]) or numerical (for arbitrary shapes) that solve the quasistatic surface integral equation for the electric potential using method of moments [29,30]. The range of shapes for which the equivalent spheroid assumption is reasonable is given in [30] for Rayleigh scattering. They found that for convex shapes (e.g., cylinders, cones) especially with an axis of symmetry, the equivalent spheroid is reasonable, but shapes that have concave surfaces or are multiply-connected (e.g., torus) cannot be approximated by spheroids. In the mid-1970s, Gans' method was frequently used for rain drops, solid ice "plates" (oblates with axis ratios of 0.05 or less), and needles (prolates with axis ratios of 20 or higher). The effective medium approximations for the dielectric constants of inhomogeneous particles such as snow aggregates (ice-air mixture) or wet snow (ice-water-air mixtures) or spongy hail (ice-water mixture) are generally based on [31] but they are valid only if the inclusions or "grains" within the matrix material (e.g., ice inclusions in water) are small so that they can be treated as dipoles. The formulas do account for interaction between dipoles as in the Clausius-Mossotti equation (see [32]) so are valid for dense packing of the inclusions within the matrix. Thus, Gans' method for spheroids combined with effective medium approximations were often used to model observed polarimetric signatures [13].

For non-Rayleigh scattering, numerical methods such as T-matrix for rotationally symmetric shapes have been available since the mid-1970s [33,34]. Charles Warner later mentioned to V.N.B. that by chance he and A. Hizal were sharing office space and Hizal casually mentioned to him that he had developed T-matrix code for scattering by spheroids and asked whether there was any application for it. Warner recognized its value, to the best of V.N.B.'s recollection, rewrote the code, and used it to calculate scattering by oblate rain drops [34]. The two-layer T-matrix [35,36] has been used for water-coated spheroidal hail or melting conical graupel $[37,38]$. The scattering by arbitrary shaped particles using the method of moments solution of the surface electric field integral equation was used for disks (solid ice plate-like crystals) [39]. For inhomogeneous particles the method of moments solution of the volume integral equation was well-developed in the electrical engineering community by the mid-1970s but not used by the radar meteorology community. However, the Fredholm integral equation method 
used by the radiowave propagation community is based on the volume integral equation for the electric field interior to the particle [40]. Both volume and surface integral formulations fall in the class of Fredholm integral equations of the second kind involving the tensor free space Green's function which is singular due to the self-term which is usually evaluated analytically. The method in [40] uses a Fourier transform approach in which the transformed volume integral equation is nonsingular. The case of the ellipsoid afforded some simplifications so the code developed was restricted to spheroids and ellipsoids and was applied to ice crystal scattering by [41]. Perhaps this restriction limited more widespread use of this method. This is unfortunate as it was shown to satisfy the Schwinger variational principle and is thus known to be convergent and numerically stable [40].

The discrete dipole approximation (DDA) [42]), which also falls in the class of volume integral equations (but formulated using the concept of the "exciting field"), was used for $m m$-wave scattering by complex-shaped ice crystals and rimed aggregates but not frequently during the period covered in this article [43]. A comparison of DDA for hexagonal plates and columns (of solid ice found in cirrus clouds) with volume-equivalent oblate and prolate spheroids was done by [44]. Using the DDA as reference, they showed that errors in backscatter cross-sections at $\mathrm{H}$ and V-polarizations computed with spheroid approximations were $<15 \%$ at $35 \mathrm{GHz}$ (for typical sizes of crystals in cirrus clouds).

Whereas polarization agility and/or diversity were nascent in radar meteorology, in parallel significant work was ongoing in the remote sensing community. Specifically, airborne polarimetric synthetic aperture radar observations of ground features including cities, fields, and forests were made. Moreover, theoretical works aimed at studies of rigid bodies with possible tactical applications were in progress. Wolfgang Boerner, from the University of Illinois at Chicago, organized a NATOsponsored workshop in 1998 in Bad Windsheim, Germany. He invited representatives from the three communities to facilitate exchange of information. The presentations were published in a two-volume book edited by Wolfgang Boerner [45]. This book contains two hundred pages on radar polarimetry for meteorological observations.

\section{Ohio State-Illinois Water Survey Collaboration}

Thomas Seliga (T.S.) was Director of the Atmospheric Sciences Program within the Electrical and Computer Engineeringdepartment at Ohio State University (OSU) at the time when one of the authors (V.N.B.) joined him as a graduate student in 1973. The problem that T.S. posed was the measurement of rain rate without invoking $R(Z)$ power laws but via estimation of the intercept $\left(\mathrm{N}_{0}\right)$ and median volume diameter $\left(\mathrm{D}_{0}\right)$ of an assumed exponential drop size distribution. At that time T.S. and V.N.B. were aware of (1) the wind-tunnel data of [46], which gave a simple linear expression for drop axis ratio $(b / a)$ versus $\mathrm{D}$ in the form $b / a=1-\beta D$ and (2) the conclusions in [47] that rain drops formed an anisotropic propagation medium with high degree of orientation. T.S. suggested a simplistic view of Rayleigh scattering by oblates arguing that an $\mathrm{H}$-polarized wave would induce an electric dipole moment and related radar cross-section varying as $a^{6}$ ( $a$ being the major axis) whereas a V-polarized wave induced moment and related cross-section as $b^{6}$ ( $b$ the minor axis). Thus, small deviations in axis ratio would be amplified if the ratio $(b / a)^{6}$ were considered. A colleague suggested we use Gans' method, as in [48], for scattering by oblate spheroids. Subsequently, the differential reflectivity technique for estimating $R$ was presented by V.N.B. at an URSI conference in Boulder in 1974 followed by [49] where $Z_{D R}$ versus $\mathrm{D}_{0}$ and $\log \left(\mathrm{Z}_{\mathrm{h}} / \mathrm{N}_{0}\right)$ versus $\mathrm{D}_{0}$ were given on the same plot to emphasize the retrieval of $\left(\mathrm{N}_{0}, \mathrm{D}_{0}\right)$ and hence R. T.S. also included two block diagrams to measure $Z_{D R}$. The first was based on polarization agility or pulse-to-pulse switching between $\mathrm{H}$ and $\mathrm{V}$ polarizations and sequential reception of the $\mathrm{H}$ and $\mathrm{V}$ polarized components of the backscattered wave via the same receiver. The second was polarization diversity, whereby the transmitted wave was fixed at slant linear $45^{\circ}$ polarization and simultaneous reception of the $\mathrm{H}$ and $\mathrm{V}$-polarized components were made via two receivers. T.S. knew from his prior research on wave propagation in the ionosphere at Penn State that receivers could be built that measure small differential amplitude (and differential phase shifts) very accurately, hence the assumption in [49] was made that $Z_{\mathrm{DR}}$ could be measured to within $0.2-0.5 \mathrm{~dB}$. 
While taking an advanced EM class at OSU, V.N.B. was introduced to Waterman's T-matrix method of scattering by conducting bodies of revolution, and realized that it could be applied to oblate raindrops. A fortuitous event led Peter Barber to send his T-matrix code to OSU for this application [33]. The National Hail Research Experiment (NHRE) was ongoing and there appeared to be interest in scattering by nonspherical melting hail (i.e., water-coated hail) which could be solved using a two-layer T-matrix approach $[36,37,50]$. At about the same time, Humphries' PhD thesis [51] on depolarization effects of rain on circular polarized waves inspired [52] to suggest that differential propagation phase termed as $\Delta \Phi$ normalized by $\mathrm{N}_{0}$ could be related to $\mathrm{D}_{0}$ which together with differential reflectivity might provide better accuracy in estimation of $\mathrm{R}$. The simple formula in [43] for coherent wave propagation was used along with T-matrix calculations for the forward scatter amplitudes. However, at that time an algorithm to estimate $\Delta \Phi$ using pulse-to-pulse switching data was not available (that appeared later in a conference paper by Mueller) [53].

In 1977, Ramesh Srivastava, who was Principal Investigatorfor the CHILL facility, arranged a science meeting at the University of Chicago where Gene Mueller thought it feasible to use "slow" switching ( $0.5 \mathrm{~s}$ switch time) between alternate batches of (1500) $\mathrm{H}$ and $(1500) \mathrm{V}$ pulses to measure $\mathrm{Z}_{\mathrm{DR}}$. In the mid-1950s, Gene had already worked on drop shapes and scattering by spheroids, which appears to have played a role in his enthusiasm. The CHILL antenna had a feed/OMT for dual-pol capability but unused as yet. The feed/OMT was sent to OSU where the E/H-plane patterns were measured at the Electroscience Laboratory. The feed was a dual-mode Potter horn that gave well-matched E/H-plane patterns and the OMT had good port-to-port isolation. The antenna engineering staff indicated the feed was good for our application. It might be of interest to know that T.S. consulted with the famous antenna expert John Kraus (inventor of the helical antenna and Big Ear Radio Telescope, who was retired but still at OSU at that time) about dual-polarization radar measurements and Kraus' response was "to keep it simple". In retrospect, this was sound advice as there is no simpler concept than the two systems for measuring $Z_{\mathrm{DR}}$ outlined by T.S. in [49]. In the summer of 1977 and during the waning days of the Severe Environmental Storms and Mesoscale Experiment (SESAME) project in Oklahoma (OK), the first "slow"-switched $Z_{\mathrm{DR}}$ data in rain were obtained which showed that it could be measured and fell in the range predicted from theory [11]. In 1981, the first high-power switchable ferrite circulator (from an NSF grant awarded to Ohio State) was installed on the CHILL radar enabling measurement of "fast"-switched $Z_{\mathrm{DR}}$. Seliga and Mueller presented these data in 1982 at a URSI conference in the UK.

A series of articles on the microphysical interpretation of $Z_{\mathrm{DR}}, C D R$, and specific differential phase in terms of, respectively, the reflectivity-weighted mean axis ratio, the mean and variance of the latter, and the product of $\mathrm{W}$ (rain water content) and the deviation of the mass-weighted mean axis ratio from unity were published in [54,55]. The axis ratio distributions from Jones' [56] camera data which are extreme and not supported by later drop shape studies were used. Nevertheless, the interpretations are, in essence, applicable given the $p d f$ of axis ratios. Assuming a linear relation of the form $b / a=1-\beta D$, the $Z_{\mathrm{DR}}$ and specific differential phase were related to the ratio of $7^{\text {th }}$ to $6^{\text {th }}$ moments of the drop size distribution (DSD), and to the product of $W, \beta$, and the ratio of the $4^{\text {th }}$ to $3^{\text {rd }}$ moments (caveat is that $\beta$ from Jones' data is too low and biased to mean drop axis ratios closer to sphericity) $[54,55]$.

\section{Ohio State and Appleton Laboratory Collaboration}

In 1977 a fortuitous meeting between Martin Hall of the Appleton Laboratory in the UK and Thomas Seliga at an URSI conference in La Baule, France, led to "fast" pulse-to-pulse switched $Z_{\mathrm{DR}}$ measurements. A surplus air-surveillance S-band radar had been installed on the $25 \mathrm{~m}$ reflector antenna at Chilbolton, UK, for studies of rain attenuation along slant paths as part of radiowave propagation experiments. It was recognized that the parameters of the DSD were needed to estimate attenuation (which could then be scaled to $\mathrm{K}_{\mathrm{u}}$-band) so the decision was taken by Martin Hall and the chief engineer, Steve Cherry, to build a motor-driven rotary vane switch integrated with a turnstile polarizer coupled to a scalar feed as one unit. A small NATO grant enabled collaboration between Appleton and OSU. In 1978, Martin and Steve came to OSU with time series of power samples at $\mathrm{H}$ and V polarizations 
with antenna stationary and from a single movable range gate. OSU was tasked with deriving the statistics of the normalized amplitude ratio of the $\mathrm{H}$ and $\mathrm{V}$ signals (the radar was incoherent) as a function of the correlation between the pulse pairs in the simpler case of uncorrelated sequence of $(\mathrm{H}, \mathrm{V})$-pairs. An article on the bivariate chi distribution presented sufficient information to obtain the $p d f$ of the normalized amplitude ratio with the correlation coefficient as a parameter. The agreement between theory and time-series analysis was unexpectedly good especially for correlation coefficients close to 1 . The analysis was written up in a conference paper which was presented at a URSI conference organized by Profs. Riedler and Randeu in Graz, Austria [57]. At that conference, McCormick wrote down a formula for $Z_{\mathrm{DR}}$ in terms of the elements of the coherency matrix at circular polarization [58]. As mentioned earlier, [24] derived the same after "correcting" for differential propagation shift in rain (see, also) [59].

During a visit by V.N.B. to Appleton Labs in 1982, Steve Cherry had collected a substantial set of time-series data which enabled a more detailed study of the statistical fluctuations of $Z_{\mathrm{DR}}$ and the "optimal" estimator for $Z_{\mathrm{DR}}$ starting from the $4 \times 4$ correlation matrix of the complex voltages. The expressions for mean and variance of $Z_{D R}$ were adapted from $[60,61]$ resulting in the article [62].

\section{Rutherford-Appleton Laboratory/Chilbolton Radar}

A landmark article in Nature describes in more spatial detail (afforded by the narrow $0.25^{\circ}$ beam) the application of $Z_{\mathrm{DR}}$ [12]. It included detection of ice (graupel) melting to rain in convection, snow aggregates melting to rain in stratiform events (with bright-band), and the spatial variability of the DSD parameters $\left(\mathrm{N}_{0}, \mathrm{D}_{0}\right)$. This and the table of particle type classification based on $\left(\mathrm{Z}_{\mathrm{H}}, \mathrm{Z}_{\mathrm{DR}}\right)$ were largely responsible for rapid acceleration of polarization agile radar development in the US [63] and in Europe (initially France, then Russia, Italy, and Germany, see Section 8). In 1982, an URSI Commission F symposium on Multiple-Parameter Radar Measurements of Precipitation [64] was held in Bournemouth, UK, with Martin Hall as the Symposium Chair. Seventy-nine attendees from 15 countries participated in ushering a new chapter in weather radar polarimetry. Subsequently, the conference papers were published in a Special Issue of Radio Science in 1984, edited by Martin Hall [65].

The article by [66] in that special issue again stands out for providing details of the vertical profile of $Z_{\mathrm{H}}$ and $Z_{\mathrm{DR}}$ with height in stratiform rain with bright-band. A layer of positive $Z_{\mathrm{DR}}$ up to $4 \mathrm{~dB}$ at $-10^{\circ} \mathrm{C}$ was inferred to be caused by horizontally oriented plates $\left(-10^{\circ} \mathrm{C}\right.$ being a growth region of dendritic crystals by vapor deposition). At lower heights to $-5^{\circ} \mathrm{C}$, aggregation was inferred by increasing $\mathrm{Z}_{\mathrm{H}}$ (larger maximum sizes) but lower $\mathrm{Z}_{\mathrm{DR}}$ (lower bulk density and irregular shapes). The peak in $Z_{\mathrm{DR}}$ (around $1.3 \mathrm{~dB}$ ) due to partially melting snow was located near the base of bright-band just prior to the rapid transition to fully melted smaller rain drops. Another important example (which they termed as a "rare" occurrence) was a narrow column of high $Z_{\mathrm{H}}$ and $\mathrm{Z}_{\mathrm{DR}}$ extending to $1.5 \mathrm{~km}$ above the melting level in convection and interpreted as supercooled rain drops carried up in the updraft. The above two examples, just based on $\left(\mathrm{Z}_{\mathrm{H}}, \mathrm{Z}_{\mathrm{DR}}\right)$, inspired substantial research on the microphysical origins of the full complement of polarimetric signatures in winter storms and in positive $Z_{\mathrm{DR}}$ columns in convective storms that is still ongoing.

In the same special issue, Chilbolton radar data were used to construct a frequency distribution of $\left(Z_{\mathrm{H}}, \mathrm{Z}_{\mathrm{DR}}\right)$-pairs in rain and a rain-ice separation boundary was identified [67]. Data pairs that fell outside the rain area were inferred to be graupel/hail depending on the $Z_{H}$ values. This led to defining the quantitative HDR hail signature in [68] but, more importantly, to defining two-dimensional membership functions for rain in fuzzy-logic schemes [69-71].

Another article in the same special issue described the use of optical array probes on the University of Wyoming King Air [72]. Based on Thomas Seliga's suggestion, one of the probes was oriented in the conventional manner with vertical optical axis (giving the top view) and another with horizontal axis (side view). When penetrating light rain shafts, the top-view images were circular while the side-view images were elliptical. Careful analysis of the axis ratios using the side view images by William Cooper showed good agreement on average with the axis ratios from Green's theory for 
$2<\mathrm{D}<4 \mathrm{~mm}$ [73]. The mean axis ratio versus $\mathrm{D}$ relation is vital for $\mathrm{Z}_{\mathrm{DR}}$ estimation of $\mathrm{D}_{0}$ and subsequently much research has been done to establish this on a firmer basis including wind-tunnel measurements [74] and 2D-video disdrometer measurements [75] as well as the numerical prediction of equilibrium shapes [76]. A curve fitting approach using available axis ratio data from a variety of somewhat uncertain experimental and laboratory results (perhaps with compensating errors) has since been widely used [77].

Using the Chilbolton radar, a seminal paper on observations of $Z_{\mathrm{DR}}$ in the ice region of a stratiform rain event with aircraft-mounted particle imaging probes was published [78] which largely corroborated the inferences in [66]. Large positive $Z_{\mathrm{DR}}$ were found in layers of "plate-like" crystals with low $Z_{\mathrm{H}}$, but when mixed with larger snow aggregates they found a "masking" effect, i.e., $Z_{\mathrm{DR}}$ tended to $0 \mathrm{~dB}$ as $Z_{\mathrm{H}}$ increased due to aggregation [78]. The shapes of snow aggregates (which dominates the $Z_{\mathrm{DR}}$ ) are highly irregular with effective permittivity much lower than solid ice, both of which cause $Z_{\mathrm{DR}}$ to be close to $0 \mathrm{~dB}$. Their paper spurred substantial polarimetric applications in winter precipitation using $\mathrm{S}$, $\mathrm{C}$, and X-band systems.

At about 1985, Anthony Illingworth (University of Manchester UK) infused new energy to the Chilbolton radar research by encouraging a steady stream of students interact with the RAL staff (John Goddard and Jon Eastment) and by focusing on cloud physics. A seminal article describes the possible microphysical origin of $\left(\mathrm{Z}_{\mathrm{H}}, \mathrm{Z}_{\mathrm{DR}}\right)$ signatures in isolated echoes from initial stage (low concentration of large drops formed by coalescence processes) to vigorous updraft stage where positive $Z_{\mathrm{DR}}$ columns extend to about $-10^{\circ} \mathrm{C}$; this indicates lofting of rain into the cold part of the cloud [79]. They also describe the dissipating stage where $\left(\mathrm{Z}_{\mathrm{H}}, \mathrm{Z}_{\mathrm{DR}}\right)$ in the rainshaft are consistent with exponential DSDs. The ultragiant aerosol hypothesis in [80] and a simple coalescence growth model was used to predict the $\left(\mathrm{Z}_{\mathrm{H}}, \mathrm{Z}_{\mathrm{DR}}\right)$ [81]. The evolution from initial echo stage where low concentrations of large drops formed via coalescence was compared with radar measurements and found to be in good agreement [81].

Sometime in 1986-1987, a second receiver was added to the radar by Jon Eastment permitting linear depolarization ratio (LDR) measurements. Statistics of $\Delta \mathrm{Z}_{\mathrm{H}}$, which is the difference between the peak value of $Z_{\mathrm{H}}$ in the bright-band (BB) and the rain below, was given in [82]. The mode of $\Delta \mathrm{Z}_{\mathrm{H}}$ was about $10 \mathrm{~dB}$ which occurred with large LDR values of about $-15 \mathrm{~dB}$ indicating wet snow. In contrast, in stratiform rain with weak embedded convection the $\Delta \mathrm{Z}_{\mathrm{H}} \approx 0 \mathrm{~dB}$ with lower $\mathrm{LDR}<-20 \mathrm{~dB}$ indicative of more compact rimed snow or graupel melting (with weak or no BB signature) to form rain. The engineering modifications to the Chilbolton radar circa 1994 are described in [83], which includes Doppler velocity and differential phase with all variables displayed in real-time.

\section{Colorado State-NCAR-Ohio State/Penn State Collaboration}

In 1983, the Army Research Office funded three institutions (listed above) for continuing polarimetric studies using the NCAR CP2 dual-wavelength radar. Earlier in 1981, J. Vivekanandan joined CSU as a PhD student, V. Chandrasekar in 1982, Joseph Turk in 1986 and John Hubbert in 1988, all under VNB. Thomas Seliga provided the second high-power switchable ferrite circulator, which was installed on the CP2 radar under the leadership of Charles Frush, who was able to "tune" the transmit and receive port-to-port isolation to better than $30 \mathrm{~dB}$ (the manufacturer's specification was minimum $20 \mathrm{~dB}$ of isolation). The field program MAYPOLE (May Polarization Experiment '83) had the NCAR Wyoming King Air with cloud and precipitation probes mounted with $\mathrm{H}$ and $\mathrm{V}$ optical axes (4 probes in all) for in-situ validation.

In 1984, Frush also led the installation of a second X-band antenna and receiver on the CP2 pedestal to measure the cross-pol reflectivity and thus LDR (the copol reflectivity was measured by the original X-band part of the dual-wavelength system). This second antenna was rotated by $90^{\circ}$ relative to the original antenna. Both antennas were military surplus coaxial Cassegrain design with a polarization twist sub-reflector, which greatly reduced blockage, resulting in low side lobes $(<-30 \mathrm{~dB})$. The two-way integrated cross-polar ratio was around $-32 \mathrm{~dB}$ based on antenna pattern measurements 
at the National Bureau of Standards. However, the S-band antenna had high close-in side lobe levels (around $-23 \mathrm{~dB}$ ) in the principal planes due to blockage by the 4 support struts which were located in these planes. Apart from the side lobe levels, the mismatch in the close-in side lobe levels between $\mathrm{H}$ and $\mathrm{V}$-polarizations caused large $\mathrm{Z}_{\mathrm{DR}}$ errors in the presence of even modest spatial gradients of $Z_{\mathrm{H}}[84,85]$. At the suggestion of Thomas Seliga, the support struts were rotated by $45^{\circ}$ in late 1986, which resulted in much better $Z_{\mathrm{DR}}$ data quality in the presence of gradients [86].

The first article on hail detection using $Z_{\mathrm{DR}}$ hail signature in strong convective storms was published in 1984 [87]. In a two-part series of articles [88,89], Part 1 used the detailed melting model of graupel [90] together with T-matrix (and two-layer T-matrix) scattering calculations, CP2 radar measurements, and aircraft data to show good agreement in the vertical profiles of $Z_{\mathrm{H}}, Z_{\mathrm{DR}}$ and LDR between radar and model in two convective cases. This was perhaps the first such coupling of microphysical model output to EM scattering model specifically for melting graupel (the "dry" graupel size distribution aloft and sounding for the melting model were initialized with aircraft data). In the Part 2 article [89], CP2 radar data were used to compare the spatial distribution of $Z_{\mathrm{DR}}, \mathrm{LDR}$, and dual-wavelength signatures in several hail storms. They showed very good spatial overlap of the signatures as well as consistency with scattering model predictions. The vertical structure of dual-wavelength hail signatures $(>5 \mathrm{~dB})$ above $0{ }^{\circ} \mathrm{C}$ level, enhanced LDR $(>-20 \mathrm{~dB})$, due to wet hail aloft and prominent $Z_{\mathrm{DR}}$ hail signatures below the melting level demonstrated the value of combining polarimetric and dual-wavelength radar data.

In 1986, V. Chandrasekar and Peter Brockwell of the Statistics Department at CSU devised a method to simulate polarimetric radar signal fluctuations assuming the Doppler spectra at $\mathrm{HH}$ and VV polarizations were Gaussian with specified correlation coefficient [91]. This procedure simulates the statistical fluctuations in $\mathrm{Z}_{\mathrm{H}}, \mathrm{Z}_{\mathrm{DR}}$ and differential phase more realistically (depending on wavelength, spectral width, number of sample pairs, and pulse repetition time as compared to simply assuming ad hoc Gaussian errors for the radar variables. The goal was to understand, using simulations, the error structure of polarimetric radar estimation of rain rate using different algorithms based on $\left[Z_{\mathrm{H}}, Z_{\mathrm{DR}}\right.$, $K_{D P}$ ] [92]. For disdrometer simulations, the DSD was modelled as the product of $N_{T}$ and the $p d f(D)$ where $\mathrm{N}_{\mathrm{T}}$ is the total number of drops per unit volume assumed to be Poisson distributed and the $p d f$ (D) was assumed to be the gamma $p d f$ [93]. This form involves "double" random variables so the mean and variance of moments of the DSD, and correlation between moments, involved random sums over random number of total drop counts and random drop sizes. In [93], simulations of disdrometer-induced fluctuations in Z-R were compared with simulations of radar Z fluctuations with $R$ (with full range of expected physical variations included). They showed quantitatively that disdrometer Z-R correlations would be much higher relative to radar-based Z-R correlations under ideal conditions [93]. A three-part series of papers followed on the error structure of radar and disdrometer measurements of rainfall using $\mathrm{Z}_{\mathrm{DR}}, \mathrm{X}$-band specific attenuation, and differential propagation phase [94-96].

In 1986, the CP2 radar was moved to Huntsville, AL, with two NCAR C-band radars as part of a triple Doppler network for the Microburst and Severe Thunderstorm (MIST) project headed by the late Theodore Fujita. The PIs for the CP2 radar were V.N.B. and Gregory Forbes from Penn State while Roger Wakimoto was in charge of radar operations. The South Dakota School of Mines and Technology (SDSM\&T), T-28, and University of North Dakota (UND) Citation aircraft also participated for in situ measurements of precipitation in the interior of $>50 \mathrm{dBZ}$ convective cells. MIST provided the first opportunity to deploy a polarimetric dual-wavelength radar in a subtropical climate. Very quickly it was apparent that warm rain processes in early echoes (low $Z_{H}$ and positive $Z_{D R}$ ) were ubiquitous as were positive $Z_{\mathrm{DR}}$ columns extending to $-10{ }^{\circ} \mathrm{C}$ in more vigorous convective updrafts. It was David Johnson who alerted V.N.B. (via Roy Rasmussen) to look for positive $Z_{\mathrm{DR}}$ in early echoes (with warm cloud bases) and their evolution based on his ultragiant aerosol hypothesis. The freezing of supercooled rain as inferred from the disappearance of the positive $Z_{D R}$ columns was almost always followed by a lightning discharge which was monitored in real time by Steve Goodman from NASA/Marshall to 
his great excitement. Dusan Zrnic happened to visit the $\mathrm{CP} 2$ radar during MIST and he, too, was greatly impressed by the real-time observations of positive $Z_{\mathrm{DR}}$ column evolution. The time evolution of an isolated microburst-producing storm was described in [97] from early echo stage to vigorous growth stage to heavy precipitation loading by small wet hail in the dissipating stage along with cloud photos of the evolution on which contours of $Z_{\mathrm{H}}$ were overlaid (true to the Fujita style of analysis and hand-drawn graphics by Roger). In a landmark article, the same storm was analyzed using triple Doppler synthesis in addition to $Z_{D R}$, specific attenuation at $X$-band $\left(A_{x}\right)$, and dual-wavelength ratio (DWR) hail signatures from early echo to dissipating stage [98]. The time-height cross-sections of multiple radar observables $\left(Z_{\mathrm{H}}, \mathrm{Z}_{\mathrm{DR}}, \mathrm{A}_{\mathrm{x}}\right.$, DWR, and updraft speeds) gave an excellent opportunity to synthesize the "bulk" microphysical evolution of the storm. The co-authors, Harold Orville and Fred Kopp of SDSM\&T, used their two-dimensional time-dependent cloud model initialized with the morning sounding to compare with the radar observations [98]. By and large, the model microphysical evolution was consistent with radar observations during the vigorous growth and microburst-producing phases.

Around 1987, the Battan Memorial Conference with a commemorative volume of review papers on Radar in Meteorology was being planned by David Atlas, Robert Serafin, and Rit Carbone, which was published by the AMS in 1990. The early years of dual-polarization radars were reviewed in [99]. The status of dual-polarization radar research, at that time including circular and linear polarization configurations, was also reviewed [100]. Hendry built a comprehensive table listing the system characteristics of nearly all of the dual-polarized radars which were in use or had just been decommissioned [100].

The microphysical inferences of polarimetric signatures using CP2 radar data especially positive $\mathrm{Z}_{\mathrm{DR}}$ columns extending several $\mathrm{km}$ above the $0{ }^{\circ} \mathrm{C}$ level and the enhanced LDR "cap" at the column top signifying mixed phase region (supercooled rain and wet ice) which can rapidly evolve into severe hailstorms were reviewed in [101]. They also showed the vertical structure of dual-wavelength and LDR signatures in a hailstorm and discuss the different scattering aspects, i.e., non-Rayleigh scattering at X-band versus depolarization due to wet, non-spherical hail.

One of the last deployments of the CP2 radar in the US was in Florida in 1991 for the Convective and Precipitation/Electrification (CaPE) project which involved the NOAA P-3 and T-28, as well as the NCAR and Wyoming King Airs. Multiple Doppler synthesis, radar observables [ $\left.Z_{H}, Z_{D R}, A_{x}, L D R\right]$, and in situ microphysical and electric field mill data were used to study the evolution of thunderstorm cells [102]. The mixed phase region inferred by overlapping enhanced LDR "cap" and a core of enhanced specific attenuation on top of positive $Z_{\mathrm{DR}}$ columns (at about $-10^{\circ} \mathrm{C}$ ) was validated by aircraft penetrations. Storm electrification was positively correlated with the first appearance of the mixed phase signatures aloft [103].

In 1994, a Workshop on Weather Radar Polarimetry for Research and Operations was held at NCAR with 29 scientists in attendance [104]. To set the stage and to foster discussion, 16 short presentations were made highlighting the progress made so far and future avenues needing research prior to operational systems development. There was good motivation for improved quantitative precipitation estimation (QPE) from the weather agencies and for hydrological applications represented by Bob Saffle. The need for validation of rainfall algorithms using a dense network of gages was emphasized, including the use of differential propagation phase when rain is mixed with hail in strong convection. However, the important agenda was to replace the CP2 system with a new, easily transportable S-band radar without radome, with a high-quality antenna and feed and new digital intermediate frequency (IF) receivers and real-time displays of all the polarimetric variables.

In 1995, the CSU-CHILL radar with a new parabolic reflector antenna and two transmitter system with dual-receivers was able to deliver high quality polarimetric data including LDR with system limit approaching $-34 \mathrm{~dB}$. In addition, measurements of the correlation between the copol and cross-pol signals were available. Thus, the full covariance matrix (three real powers and three complex correlations) data were available with high accuracy for the first time. Among the first 
articles that followed [105] was a description of the distinct polarimetric signatures in a supercell storm. A chase van equipped for manual collection of hail, and instrumented with a rain gauge, intercepted the storm core for $50 \mathrm{~min}$. The loud pounding of golf ball-sized hail while trying to take notes on changing hydrometeor types as well as collecting hail every few minutes in plastic bags with time stamps, chilling them in hexane, and bagging them in dry ice was an unforgettable experience for the two nonmeteorologists, V.N.B. and John Hubbert. Locations of peak horizontal convergence (from dual-Doppler synthesis) were found to be centered on well-defined positive $Z_{D R}$ columns. An enhanced LDR "cap" area on top of the positive $Z_{D R}$ column was interpreted as a region of large drops mixed with partially frozen and frozen hydrometeors, consistent with [101]. A positive $\mathrm{K}_{\mathrm{DP}}$ column on the western fringe of the main updraft was hypothesized to be the result of copious numbers of small drops (1-2 mm) shed by wet hailstones. Swaths of large hail at the surface (inferred from LDR signatures) and positive $Z_{D R}$ at $3.5 \mathrm{~km}$ AGL suggested that potential frozen drop embryos were favorably located for growth into large hailstones.

The microphysics and kinematic evolution of convective storms studied so far with CP2 and CSU-CHILL radars took a major leap towards understanding the electrical characteristics [106]. The dual-pol radar-inferred graupel volume suspended in a vigorous updraft in upper portions of the storm was strongly correlated with in-cloud (IC) lightning flash rate. In addition, the radar-inferred maxima in the hail rate were related to peaks in the cloud-to-ground (CG) lightning flash rate. Both correlations were consistent with the non-inductive charging mechanism, which is caused by collisions between graupel/hail particles and ice crystals in the presence of supercooled water. The research published in [106] led to substantial further research on application of polarimetric radar for storm electrification studies.

\section{National Severe Storms Laboratory}

The NSSL is the research arm of the US National Weather Service (NWS) with the mission of advancing the understanding of weather processes, research to improve forecasting and warning techniques, and development of operational applications. NSSL is NOAA's primary radar laboratory for advancing radar technology, the prime example being NSSL's role leading up to the deployment of the WSR-88D Doppler systems (NEXRAD) by the NWS. The next technology to attract the attention of Richard Doviak (R.D., leader of the Advanced Techniques Group) was dual-polarization, the potential of which was not explored as yet by NSSL. One of the authors (D.Z.) joined NSSL in 1978 and was assigned to lead dual-polarization radar studies. Both R.D. and D.Z. attended the first Workshop on Dual-Polarization Radar in 1980 chaired by Metcalf and Humphries. In 1979, R.D. and D.Z. visited with Humphries in Alberta to evaluate their S-band circularly polarized radar. They concluded that the coherency matrix using circular basis could not be easily related to bulk precipitation properties and decided in favor of dual-linear polarizations.

In 1981, NSSL placed an order with Raytheon for the same ferrite switchable circulator as installed on CHILL and CP2 radars. The ferrite phase shifters were known to be especially sensitive to temperature and it took Raytheon three trials to meet the specifications, but fell short. The switch was delivered in 1983 and its characteristics were measured in the laboratory and later reported in [107]. NSSL chief engineer Dale Sirmans, with John Carter and Mike Schmidt, "tuned" the switch for stable and near optimal performance and installed it on the NSSL radar in Cimarron, OK. At that time D.Z. did not realize the full potential of polarization agile "fast"-switched data. He had the foresight to decide that time series of the complex voltages $(\mathrm{I}+\mathrm{jQ})$ at $\mathrm{H}$ and $\mathrm{V}$-polarizations gave the most flexibility in signal processing for computing polarimetric variables other than $Z_{D R}$. At slow antenna scan speeds, it was possible to acquire data from tens of kilometers in range.

In 1983, M. Sachidananda (M.S.) from India came to NSSL as an NRC associate to work with D.Z. A landmark article by M.S. and D.Z. [108] was published in 1985 where they (1) computed the $\operatorname{var}\left(Z_{D R}\right)$ in the "fast"-switched mode accounting for correlation between all the samples in the $H, V$ sequences (a generalization) of [62]), (2) where they related the zero-lag correlation coefficient $\left|\varrho_{\mathrm{hv}}(0)\right|$ to 
physical properties of the scatterers, and (3) computed the var $\left(Z_{D R}\right)$ in the mode where slant linear $45^{\circ}$ polarization is transmitted with simultaneous reception of $\mathrm{H}$ and $\mathrm{V}$-polarized components of the elliptically polarized backscattered electric field (suggested) in [49]. In this case, the $2 \times 2$ coherency matrix has 2 power terms and one complex correlation which by definition is at zero lag or $\varrho_{\mathrm{hv}}$. The var $\left(Z_{\mathrm{DR}}\right)$ in this mode involves the term $1-\left|\varrho_{\mathrm{hv}}\right|^{2}$ which implies that if $\left|\varrho_{\mathrm{hv}}\right|^{2}$ is sufficiently close to 1 , then the var $\left(Z_{D R}\right)$ will reduce correspondingly. They estimated that $\left|\varrho_{\mathrm{hv}}\right|^{2}$ due to raindrop shape variations (e.g., oscillations) or drop canting would be 0.99 or larger. Any decorrelation due to mixture of particle types such as rain-hail or wet snow shapes or tornado debris or even ground clutter would lower $\left|\varrho_{\mathrm{hv}}\right|^{2}$ pointing to its utility as a useful radar measureable.

Another important paper [109] was published in 1986 where they compute the variance of differential propagation phase $\left(\Phi_{\mathrm{dp}}\right)$ based on two estimators of which the better one was given by [53] and used in polarization agile "fast"-switched radars. The derivation for the var $\left(\Phi_{\mathrm{dp}}\right)$ is complicated but the end result is that it can be measured with standard deviation of a few degrees. In both $[108,109]$ the authors drew on important works concerning pulse pair estimators of Doppler velocities [110-113] to obtain the statistics of the polarimetric variables $\left(Z_{D R}, \Phi_{d p}\right)$. In [109] they define $\Delta \Phi$ as the range derivative of $\Phi_{\mathrm{dp}}$ and show that rain rate (R) derived from $\Delta \Phi$ is less sensitive to DSD variations than Z-R relations. In a follow-up article, the field of $\Delta \Phi$ from sector PPI scans were used to illustrate the range of values and their spatial variability [26]. Later, the specific differential phase $\left(\mathrm{K}_{\mathrm{DP}}\right)$ was defined as one-half the range derivative of $\Phi_{\mathrm{dp}}$ to be consistent with the radiowave propagation literature. In 1986, M.S. departed but details of algorithms used for mean Doppler velocity, differential phase, and correlation coefficient were contained in the notes of M.S. and D.Z. Soon thereafter, D.Z. assembled these notes into a Cooperative Institute for Mesoscale Meteorological Studies (CIMMS) report [114], which was widely distributed in the US and overseas with the aim of accelerating dual-polarization research. The specific algorithms for Doppler spectral width and the decoupling of mean Doppler velocity from $\Phi_{\mathrm{dp}}$ were given in [115]. For the record, NSSL produced reports many of which are on its Web site.

N. Balakrishnan (N.B.), from the premier Indian Institute of Science (IISc) in Bangalore where he was a faculty member in Aerospace Engineering, joined NSSL as a NRC associate from 1987-1989. Both M.S. and N.B. obtained their PhD from IISc and were fellow graduate students. Soon after N.B. joined NSSL, he requested the T-matrix and two-layer T-matrix codes from V.N.B., who knew him well from past visits to IISc. Using his strong background in EM and scattering theory, N.B. made full use of these codes in innovative ways. In a seminal conference paper in 1989, a method was proposed for correcting for path integrated attenuation (PIA) using differential propagation phase especially at higher frequencies such as C-and X-bands [116]. They recognized that both the specific attenuation $(\mathrm{A})$ and the specific differential phase $\left(\mathrm{K}_{\mathrm{DP}}\right)$ were approximately related to the fourth moment of the DSD from which linear relations of the form $A=\alpha K_{D P}$ were formulated. In a similar manner, they also formulated a linear relation between specific differential attenuation between $\mathrm{H}$ and $V$ polarized waves $\left(A_{D P}\right)$ and $K_{D P}$. Simulations based on gamma DSDs were used to show the accuracy of these linear relations [117]. The latter article also provided experimental data from the polarimetric dual-wavelength CP2 radar by collecting time-series data in heavier rainfall from which X-band PIA was shown to be highly correlated with S-band $\Phi_{\mathrm{dp}}$. After range filtering they showed that specific attenuation $(\mathrm{Ax})$ was linearly related to S-band $K_{\mathrm{DP}}$ which confirmed the theoretical predictions. The straightforward correction of measured reflectivity and differential reflectivity, which are strongly attenuated due to propagation in rain, invigorated the use of polarimetric X-band weather radars (and network of X-bands) in the next two decades.

In another landmark article, time series data from the S-band NSSL radar in Cimmaron, OK, (or, $\mathrm{CIM})$ were processed to simultaneously derive $\left[\mathrm{Z}_{\mathrm{H}}, \mathrm{Z}_{\mathrm{DR}}, \mathrm{K}_{\mathrm{DP}}\right]$ in a hailstorm [118]. They made a keen inference that in a precipitation shaft composed of rain-hail mixtures, the hailstones due to tumbling or irregular shapes could be considered "isotropic" thus not contributing to the $\operatorname{Re}\left(\mathrm{f}_{\mathrm{h}}-\mathrm{v}\right)$ whereas the highly oriented oblate rain drops were the main contributors to $\operatorname{Re}\left(f_{h}-f v\right)$. This follows from coherent 
addition of the forward scattered waves from the rain and hail. Thus, hail was "transparent" to $K_{D P}$ and this permitted the estimation of the rain water content in the precipitation shaft. RHI scans through the main precipitation shaft showed the height profiles of $\mathrm{K}_{\mathrm{DP}}$ as well as the separation of hail and rain amounts [118]. The descent of the hail and heavy rain to the surface (precipitation loading in the downdraft) was reflected by a lowering (or depression) of the height of the $\mathrm{K}_{\mathrm{DP}}$ column. They also described examples of interesting positive $\mathrm{K}_{\mathrm{DP}}$ above the $0{ }^{\circ} \mathrm{C}$ level, which was interpreted as possible supercooled drops lofted upwards in the updraft [118]. Substantial research in the next two decades on this topic followed, especially in tornadic supercells.

The use of the correlation coefficient for hail detection and possible separation of small hail $(<2 \mathrm{~cm})$ from larger hail was explored in [119] using scattering simulations (including backscatter differential phase $\delta$ ) and comparing them with measurements by the CIM radar. While processing of time-series data from the CIM radar was tedious, it led to further insights of the utility of polarimetric variables. For example, RHI scan data in the stratiform region of a mesoscale convective system were used to show a "dip" in the correlation coefficient $(<0.90)$ at the base of the bright-band [120]. They also derived the variable $\delta$ by examining the range profiles of $\Phi_{\mathrm{dp}}$ and noting locations where there were localized deviations from the usual monotonic range profiles. Comparing the measured $\delta\left(\approx 5^{\circ}\right)$ with a forward scattering model they were able to infer $10 \mathrm{~mm}$ wet aggregates at the base of the bright-band. For Rayleigh scattering the $\delta \approx 0$ so the onset of non-Rayleigh scattering at S-band is about $10 \mathrm{~mm}$ or so for wet ice. The "dip" in the correlation coefficient was largely ascribed to non-zero values of $\delta$ as opposed to variance of shapes occurring at the base of the bright-band. The statistics of one estimator of $\varrho_{\mathrm{hv}}(0) \mid$ was given in the Appendix of [120] in the form of plots of the standard deviation and bias versus number of $(\mathrm{H}, \mathrm{V})$-pairs with Doppler spectrum width as a parameter. The standard deviation varied from $0.03-0.06$, which was considered sufficient for detection of hail and bright-band. The statistics of $\left|\varrho_{\text {hv }}(0)\right|$ under low signal-to-noise ratio (SNR), non-Gaussian spectra and both simultaneous and alternate sampling can be found in [121]. They found that simultaneous sampling (slant $45^{\circ}$ transmit with simultaneous reception of $\mathrm{H}$ and $\mathrm{V}$ ) gave much lower standard deviation in the range 0.003-0.006.

In the early 1990s, real-time calculations and displays of $\left\{Z_{H}, Z_{D R}, K_{D P}, \rho_{h v}\right]$ were not yet implemented on CIM radar or any other S-band radar in the US. Hence, a number of scientists in the US visited NSSL to collaborate with D.Z. on "slow" scanning time-series data which were unique at that time. They included V.N.B., V. Chandrasekar, and John Hubbert (from Colorado State) and K. Aydin from Penn State. One example was a hailstorm with supercell characteristics that was moving in the direction of the CIM radar. V.N.B., K.A., and the technician Mike Schmidt barely made it on time to start the radar as the leading edge of the storm approached. There was only time to set up RHI scans on the fly (i.e., "blind") without knowing where the storm core was located. The intense hailstorm with golf ball-sized hail and intense rain rate went overhead and lightning brought the radar "down" after $30 \mathrm{~min}$ of data collection. Polarimetric data analysis from this hail storm, and based on the range of values of the four radar variables and scattering simulations, a schematic of three vertical cross-sections depicting hydrometeor classification for three periods were shown in [122]. The classification showed the varying height of the mixed-phase or melting level; light, medium, and intense rain rates; large hail; rain-hail mixture; graupel; oriented ice crystals and bright-band along with single Doppler-based up and down drafts. While subjective, the schematic synthesized much of the knowledge available at that time in terms of self-consistency of the radar variables, scattering calculations, and melting models. D.Z. constructed a classification Table with input from NSSL staff (Burgess and Doviak) and other scientists which was included in Chapter 8 ( $2^{\text {nd }}$ edition) of [123].

Real-time calculations and displays of all the polarimetric variables and Doppler moments were completed by Allen Zahrai in 1992 including remote control of the CIM radar. It was a "first" for any polarization agile "fast"-switched system in the US. These advances, together with the exact equations for calculating the radar variables, were described in detail [124] and have been used by many organizations. Real-time data from CIM (no longer limited by "slow" antenna scan rates) over the entire unambiguous range have been used to analyze the evolution of a supercell storm [125] providing 
much more temporal and spatial detail than was possible in [122] including vertical cross-sections through the hail core and relative locations of updraft and downdrafts. Decades later, the microphysical origin of polarimetric signatures in tornadic supercells are still being studied.

In an innovative article [126], a method using polarization agile radar was proposed for measuring the three real and three complex terms of the covariance matrix by appropriately controlling the high power "fast"-switch (assuming high port-to-port isolation $>40 \mathrm{~dB}$ in both transmit and receive states). The copolar and cross-polar signals are sequentially routed to a single receiver [126]. The trade-off is between parallel processing with two receivers versus sequential processing with one receiver. Most advanced radar systems have, however, been designed with polarization agility on transmit with dual-channel receivers.

\section{France, Russia, Italy, and Germany}

The S-band radar at the University of Clermont-Ferrand in France was modified for pulse-to-pulse switching between $\mathrm{H}$ and $\mathrm{V}$-polarizations using a high power ferrite switchable circulator and a single receiver [127]. To the best of our knowledge, the first article that correlated $\left(Z_{\mathrm{H}}, \mathrm{Z}_{\mathrm{DR}}\right)$ signatures in hail with a hail pad network is [128]. Specifically, they showed the time variation of $Z_{H}$ and $Z_{D R}$ over periods ranging from 6-30 minutes over the hail pad locations. From the hail pad data, the total number per $\mathrm{m}^{2}$ and maximum size of hail were estimated for the duration of each event. They found negative $Z_{D R}$ values in the range -0.4 to $-1 \mathrm{~dB}$ with $Z_{\mathrm{H}}$ peaks of $60 \mathrm{dBZ}$ during the very heavy hail intensity. For less intense hail events, the peak $Z_{\mathrm{H}}$ was about $54 \mathrm{dBZ}$ with $Z_{\mathrm{DR}}$ in the range $0.6-2 \mathrm{~dB}$. The correlation between maximum hail size and $Z_{\mathrm{H}}$ alone was low at 0.68 but when $Z_{\mathrm{DR}}$ was included the correlation improved to 0.86 .

The Russian production incoherent $X$-band radar was modified for $Z_{D R}$ measurements using a high0power switchable ferrite circulator and a single logarithmic receiver [129]. The transmit pulse sequence was either alternating [HVHV...] or the sequence [HHVV ... ]. The second sequence was used to estimate the correlation at zero lag from 1-lag estimators but from amplitude samples from the output of a logarithmic receiver. They show $\left(\mathrm{Z}_{\mathrm{H}}, \mathrm{Z}_{\mathrm{DR}}\right]$ data from summertime convection near the St. Petersburg area collected in 1990 and largely confirm the prior inferences on positive $Z_{D R}$ columns extending, in one example, a staggering $8 \mathrm{~km}$ above the melting layer. They estimated severe differential attenuation at X-band at $0.3-0.4 \mathrm{~dB} / \mathrm{km}$, which is about a factor of 10 larger than predicted in [117]. Features such as positive $Z_{\mathrm{DR}}$ layers aloft in winter stratiform cold rain events, the peak in $Z_{\mathrm{DR}}$ at the base of the bright-band, and a "dip" in the zero lag correlation coefficient were consistent with prior results [129]. They also report on the expected values of the latter coefficient to distinguish between ground clutter and precipitation echoes.

The Italian and German C-band dual-pol radar development began in the early-mid-1980s [130,131]. Both radar systems opted for an offset feed reflector antenna (without radome) for low side lobes $(<-32 \mathrm{~dB}$ ) but the two linear cross-polar lobes can be high in the azimuthal plane (peaks of $-27 \mathrm{~dB}$ located off boresight but within the main beam) and vanishingly small in the elevation plane. Consequently, the two-way integrated cross-polar ratio was estimated (at best) to be $-35 \mathrm{~dB}$. The Italian system (Polar 55C) was designed for polarization agility (pulse-to-pulse switching between $\mathrm{H}$ and $\mathrm{V}$-polarizations) for $\mathrm{Z}_{\mathrm{DR}}$ measurements using a high-power switchable ferrite circulator but the ferrite circulator limited the isolation to $20-25 \mathrm{~dB}$ or so. The radar was installed near Florence in 1990 as part of a real-time integrated Arno River flood forecasting system. The first operational dual-pol radars (network of three) appears to have been for the Emilia Romagna weather service and they are still operational (1991-present). These C-band dual-pol systems featured dual-offset Cassegrain reflector antennas for simultaneously achieving excellent side lobes and cross-pol performance with polarization agility capability using high power ferrite circulator switches.

The German system was built by Enterprise Electronics Corporation in 1986 with the signal processors provided by SIGMET. The polarizer microwave network was unique in that a variable ratio power divider and latching ferrite phase shifters under software control could be configured 
for transmission of any elliptical polarization state. After transmission, the receive polarization state could be configured for receiving any two orthogonal polarizations (generally copol and cross-pol to the transmitted state). They had two receivers, one for each state. A detailed description of this radar system is given in [131]. Examples of range profiles of the various polarimetric variables are in [132] focusing on iterative filtering of $\Phi_{\mathrm{dp}}$ to derive $\mathrm{K}_{\mathrm{DP}}$ and $\delta$

In 1987, the NCAR King Air was flown to Germany (German Aerospace Research Establishment (DFVLR) near Munich) for in situ measurements of particles in coordination with radar observations. In one stratiform event, the aircraft flew in a layer of pristine crystals (dendrites) where $Z_{D R}$ was large in the range $3-4 \mathrm{~dB}$ with low $Z_{\mathrm{H}}(10-20 \mathrm{dBZ})$ and then flew into a region of rimed dendrites and aggregates of dendrites where the $Z_{D R}$ was reduced $(<0.5 \mathrm{~dB})$ with higher $Z_{H}(30 \mathrm{dBZ})$ confirming the earlier results in [78] but with a better suite of optical array probes and cloud water measurements. The particle images were analyzed and classified manually into pristine crystals, rimed crystals, and aggregates, and quantitative frequency of occurrences of these types were calculated which confirmed the radar inferences.

An organized line of convective cells was observed by [133] with the feeder cells ahead of the line convection showing low $Z_{H}$ and large $Z_{D R}(4-5 \mathrm{~dB})$ consistent with active coalescence processes whereas in the heavier precipitation within the convective line the $Z_{\mathrm{H}}$ was about $60-65 \mathrm{dBZ}$ with large $Z_{\mathrm{DR}}$ values of up to $7 \mathrm{~dB}$. These large $Z_{\mathrm{DR}}$ values occur at $C$-band due to resonant scattering of 6-7 mm drop sizes. The vertical profiles of $\left[Z_{\mathrm{H}}, Z_{\mathrm{DR}}, K_{\mathrm{DP}}\right.$, and $\left.\delta\right]$ showed values consistent with two-layer T-matrix calculations of water-coated hail, especially the measurements of large backscatter differential phase shift $(\delta)$ of $10-20^{\circ}$. The precipitation shaft was inferred to contain heavy rain and small melting hail with water torus $(<10 \mathrm{~mm})$.

\section{Conclusions}

It has taken nearly 35 years from the mid-70s to 2011 for dual-polarization to be given the go- ahead for operations in the US. It is the most major and complex upgrade to occur since the WSR-88Ds were deployed in the mid-1990s. This article has documented the research and institutions that spearheaded the way from circular polarized radars in the mid-70s to the polarization agile "fast"-switched radars that dominated until the mid-90s. While the seminal contributions have been summarized, perhaps too succinctly, it is our hope that the next generation of radar meteorologists will come to appreciate the early history (at least from the mid-1970s) and imbibe the flavor of the kinds of articles appearing largely (but not entirely) in the Trans. IEEE or Radio Science journals. We hope that some of the "behind the scenes" descriptions of interactions between the authors and their colleagues or serendipitous events has enlivened the article and kept the reader engaged. In the nearly two decades since 1994 the applications of radar polarimetry to meteorology has expanded way beyond what the early pioneers could have reasonably imagined including nontraditional applications such as tornado debris, volcano eruptions, insect/bird migration patterns, or smoke plumes from forest fires (this issue).

While the role of electromagnetics in dual-polarization radar is fundamental, we have taken an expansive view in this article by documenting the work that has spawned further research often many years or even decades later. The references we chose to mention are, of course, subjective to some degree but were highly regarded and cited during the period covered and continue to be cited.

Concerning polarization basis, we have come full circle, starting with circular and then agile linear $(\mathrm{H}, \mathrm{V})$ followed by the "hybrid" mode radars (such as WSR-88D). In it, the transmitted polarization state has unknown ellipticity but known $\mathrm{H}$ and $\mathrm{V}$ components, and measured is the coherency matrix of the elliptically polarized backscattered wave in the $(\mathrm{H}, \mathrm{V})$ basis using two receivers. This mode is now standard for operational weather radars and the major radar manufacturers offer this in their product line.

The microphysical inferences from polarimetric radar data during the period of this article were largely based on an observational approach with supporting scattering calculations using simple models of particle shape, orientation, or dielectric mixture formulas and at times using a 1-D detailed 
graupel/hail melting model. Validation was often sparse except during dedicated field programs involving aircraft-based instrumentation or surface disdrometers and rain gages. Dual-pol was often considered as an esoteric topic by most meteorologists and cloud physicists but that changed significantly by the early-90s with hydro-meteorologists also being entrained by prospects for more accurate QPE using $\left[Z_{\mathrm{H}}, Z_{\mathrm{DR}}, K_{\mathrm{DP}}\right]$ in some "optimized" form. We seem to have also come full circle in QPE to using specific attenuation alone as an operational algorithm for the WSR-88D (the specific attenuation being a by-product from constrained attenuation-correction algorithms using $\Phi_{\mathrm{dp}}$ ).

In the abstract of the recent article by Zhang and co-authored by 27 leading scientists, the comment is made that "The potential impact of PRD (polarimetric radar data) has been limited by their oftentimes subjective and empirical use. More importantly, the community has not begun to regularly derive from PRD the state parameters, such as water mixing ratios and number concentrations, used in numerical weather prediction (NWP) models" [134]. While there is some merit in their statement, the polarimetric radar community, by and large, has used rigorous theory, carefully conducted experiments, and solid data analysis without which the operational agencies of many countries and especially the NWS would not have gone ahead with the WSR-88D upgrade.

Most numerical microphysical schemes predict the number concentration and mass but do not predict what is important for forward modelling the polarimetric variables, e.g., shape, orientation, or particle density. Some recent schemes predict bulk physical properties such as mean density, rime mass fraction, liquid fraction on mixed phase particles, and even ice crystal aspect ratios which are closer to what is needed for forward modelling [135-137]. There has been a recent push for Lagrangian particle-based approach where the evolution of the particle size distribution is described in a truly multidimensional microphysical phase space by predicting physical properties such as ice mass, rime mass and rime volume, and liquid water fraction, as well as all warm rain processes [138,139]. This major shift in numerical microphysical models bodes well for forward modelling the polarimetric variables and ultimately to assimilation of radar data in NWP.

Dual-polarization radar topics specific to meteorology were first covered in Chapter 8 of [123]. Seventeen years later a book devoted entirely to polarimetric Doppler weather radar was published [2]. Since then, the book by Rauber and Nesbitt [140] starts with the treatment of EM waves and later devotes 50 pages to dual-polarized radar while the book by Zhang [141] is entirely on radar polarimetry covering both fundamentals and applications with rigor. The most recent book by Ryzhkov and Zrnic [3] covers the fundamentals but also offers the most comprehensive treatment of the applications of radar polarimetry to meteorology available to date. These books bode well for the next generation who can come up to speed very quickly and make original contributions to the field.

Author Contributions: Conceptualization, V.B. and D.Z.; methodology, V.B. and D.Z.; writing-original draft preparation, V.B.; writing-review and editing, D.Z.

Funding: This research was funded by the National Science Foundation, grant number AGS-1901585 to Colorado State University and by the NOAA National Severe Storms Laboratory for D.Z.

Acknowledgments: V.N.B. acknowledges useful discussions with Merhala Thurai of Colorado State University.

Conflicts of Interest: The authors declare no conflict of interest. The funders had no role in the design of this study; in the collection, analyses, or interpretation of its data; in the writing of this manuscript, and in the decision to publish these results.

\section{Abbreviations}

The following abbreviations are used in this manuscript:

$\begin{array}{ll}\text { AMS } & \text { American Meteorological Society } \\ \text { ARC } & \text { Alberta Research Council } \\ \text { CIM } & \text { Cimarron, Oklahoma } \\ \text { CIMMS } & \text { Cooperative Institute for Mesoscale Meteorological Studies } \\ \text { CSU-CHILL } & \text { Colorado State University-University of Chicago and Illinois State Water Survey } \\ \text { DDA } & \text { Discrete Dipole Approximation }\end{array}$




$\begin{array}{ll}\text { DFVLR } & \text { German Aerospace Research Establishment } \\ \text { DWR } & \text { Dual-Wavelength Ratio } \\ \text { EDR } & \text { Elliptical Depolarization Ratio } \\ \text { EM } & \text { Electromagnetics } \\ \text { HDR } & \text { Hail Detection } \\ \text { LHC } & \text { Left Hand Circular } \\ \text { MIST } & \text { Microburst and Severe Thunderstorm (Project) } \\ \text { NCAR } & \text { National Center for Atmospheric Research } \\ \text { NEXRAD } & \text { Next Generation Weather Radar } \\ \text { NOAA } & \text { National Oceanic and Atmospheric Administration } \\ \text { NSF } & \text { National Science Foundation } \\ \text { NSSL } & \text { National Severe Storms Laboratory } \\ \text { NWS } & \text { National Weather Service } \\ \text { OMT } & \text { Orthomode Transducer } \\ \text { OSU } & \text { Ohio State University } \\ \text { PIA } & \text { Path Integrated Attenuation } \\ \text { PPI } & \text { Plan Position Indicator } \\ \text { RAL } & \text { Rutherford Appleton Laboratory } \\ \text { RHC } & \text { Right Hand Circular } \\ \text { RHI } & \text { Range Height Indicator } \\ \text { SDSM\&T } & \text { South Dakota School of Mines and Technology } \\ \text { SESAME } & \text { Severe Environmental Storms and Mesoscale Experiment } \\ \text { UND } & \text { University of North Dakota } \\ \text { URSI } & \text { International Union of Radio Science } \\ \text { WSR-88D } & \text { Weather Surveillance Radar 88 Doppler } \\ & \end{array}$

\section{References}

1. Atlas, D. (Ed.) Radar in Meteorology; American Meteorological Society: Boston, MA, USA, 1990.

2. Bringi, V.N.; Chandrasekar, V. Polarimetric Doppler Weather Radar; Cambridge University Press: Cambridge, UK, 2001.

3. Ryzhkov, A.; Zrnic, D.S. Radar Polarimetry for Weather Observations; Springer: Chaim, Switzerland, 2019.

4. Metcalf, J.I.; Humphries, R.J. Workshop on Polarization Techniques in Radar Meteorology. Bull. Am. Meteorol. Soc. 1981, 62, 416-417. [CrossRef]

5. Sinclair, G. The transmission and reception of elliptically polarized waves. Proc. IRE 1941, 38, $148-151$. [CrossRef]

6. Jones, R.C. A New Calculus for the Treatment of Optical Systems. J. Opt. Soc. Am. 1941, 31, $488-493$. [CrossRef]

7. Kostinski, A.; Boerner, W. Foundations of Radar Polarimetry. Trans. IEEE Antennas Propag. 1986, 34, 1395-1404. [CrossRef]

8. McCormick, G.C.; Hendry, A. Principles for Radar Determination of Polarization Properties of Precipitation. Radio Sci. 1975, 10, 431-434. [CrossRef]

9. McCormick, G.C. On the Completeness of Polarization Diversity Measurements. Radio Sci. 1989, 24, 511-518. [CrossRef]

10. Tragl, K. Polarimetric Radar Backscattering from Reciprocal Random Targets. Trans IEEE Geosci. Remote. Sens. 1990, 28, 856-864. [CrossRef]

11. Seliga, T.A.; Bringi, V.N.; Alkhatib, H.H. Differential Reflectivity Measurements in Rain-1st Experiments. Trans. IEEE Geosci. Remote Sens. 1979, 17, 240-244. [CrossRef]

12. Hall, M.P.M.; Cherry, S.M.; Goddard, J.W.F.; Kennedy, G.R. Raindrop Sizes and Rainfall Rate Measured by Dual-Polarization Radar. Nature 1980, 285, 195-198. [CrossRef]

13. Matrosov, S.Y. Prospects for the measurement of ice particle shape and orientation with elliptically polarized radar signals. Radio Sci. 1991, 26, 847-856. [CrossRef]

14. Oguchi, T. Electromagnetic-Wave Propagation and Scattering in Rain and other Hydrometeors. Proc. IEEE. 1983, 71, 1029-1078. [CrossRef] 
15. Hendry, A.; McCormick, G.C.; Antar, Y.M.M. Differential Propagation Constants on Slant Paths through Snow and Ice Crystals as Measured by $16.5 \mathrm{GHz}$ Polarization Diversity Radar. In Annales des Telecommunications; Springer: Berlin/Heidelberg, Germany, 1981; Volume 36, pp. 133-139.

16. Hendry, A.; Antar, Y.M.M. Precipitation Particle Identification with Centimeter Wavelength Dual-Polarization Radars. Radio Sci. 1984, 19, 115-122. [CrossRef]

17. McCormick, G.C.; Hendry, A. Radar Measurement of Precipitation-Related Depolarization in Thunderstorms. Trans. IEEE Geosci. Remote Sens. 1979, 17, 142-150. [CrossRef]

18. Krehbiel, P.; Chen, T.; McCrary, S.; Rison, W.; Gray, G.; Brook, M. The use of dual channel circular-polarization radar observations for remotely sensing storm electrification. Meteorol. Atmos. Phys. 1996, 58, 65-82. [CrossRef]

19. Caylor, I.J.; Chandrasekar, V. Time-Varying Ice Crystal Orientation in Thunderstorms Observed with Multiparameter Radar. Trans. IEEE Geosci. Remote Sens. 1996, 34, 847-858. [CrossRef]

20. Barge, B.L. Hail Detection with a Polarization Diversity Radar. In Stormy Weather Group Science Report; MW-71; McGill University: Montreal, QC, Canada, 1972.

21. Barge, B.L.; Isaac, G.A. The Shape of Alberta Hailstones. J. Rech. Atmos. 1973, 7, 11-20.

22. Humphries, R.G. Depolarization Effects at $3 \mathrm{GHz}$ Due to Precipitation. Stormy Weather Group Science Report. MW-72. Ph.D. Thesis, McGill University, Montreal, QC, Canada, 1974.

23. Bebbington, D.H.O.; McGuiness, R.; Holt, A.R. Correction of Propagation Effects in S-band Circular Polarization Diversity Radars. In IEE Proceedings H (Microwaves, Antennas and Propagation); IEE-INST ELEC ENG, Michael Faraday House Six Hills Way Stevenage: Hertford, UK, 1987; Volume 134, pp. 431-437.

24. Holt, A.R. Extraction of Differential Propagation Phase Data from S-band Circularly Polarized Radars. Electron. Lett. 1988, 24, 1241-1242. [CrossRef]

25. Al-Jumily, K.G.; Charlton, R.B.; Humphries, R.G. Identification of Rain and Hail with Circular Polarization Radar. J. Appl. Meteorol. 1991, 30, 1075-1081. [CrossRef]

26. Sachidananda, M.; Zrnic, D.S. Rain Rate Estimates from Differential Polarization Measurements. Radio Sci. 1987, 4, 588-598. [CrossRef]

27. Doviak, R.J.; Zrnic, D.S. WSR-88D Radar for Research and Enhancement of Operations: Polarimetric Upgrades to Improve Rainfall Measurements; NOAA/National Severe Storms Laboratory Report: Norman, OK, USA, 1998. Available online: https://www.nssl.noaa.gov/publications/wsr88d_reports/2pol_upgrades.pdf (accessed on 30 September 2019).

28. Brunkow, D.A.; Kennedy, P.C.; Rutledge, S.A.; Bringi, V.N.; Chandrasekar, V. CSU-CHILL Radar Status and Comparison of Operating Modes. In Proceedings of the 28th Conference on Radar Meteorology, Austin, TX, USA, 7-12 September 1997; American Meteorological Society: Boston, MA, USA, 1997.

29. Van Bladel, J. Electromagnetic Fields; Revised Printing; Hemisphere: New York, NY, USA, 1985.

30. Senior, T.B.A.; Weil, H. On the Validity of Modeling Rayleigh Scatterers by Spheroids. Appl. Phys. B 1982, 29, 117-124. [CrossRef]

31. Maxwell-Garnet, J.C. Colors in Metal Glasses and in Metallic Films. Philos. Trans. R. Soc. 1904, 203, 385-420. [CrossRef]

32. Jackson, J.D. Classical Electrodynamics; John Wiley: New York, NY, USA, 1975.

33. Barber, P.C.; Yeh, C. Scattering of Electromagnetic Waves by Arbitrarily Shaped Dielectric Bodies. Appl. Opt. 1975, 14, 2684-2872. [CrossRef] [PubMed]

34. Warner, C.; Hizal, A. Scattering and Depolarization of Microwaves by Spheroidal Raindrops. Radio Sci. 1976, 11, 921-930. [CrossRef]

35. Peterson, B.; Ström, S. T-matrix Formulation of Electromagnetic Scattering from Multilayered Scatterers; Institute of Theoretical Physics: Gothenburg, Sweden, 1974.

36. Bringi, V.N.; Seliga, T.A. Scattering from an Axisymmetric Dielectric or Perfect Conductor Imbedded in an Axisymmetric Dielectric. Trans. IEEE Antennas Propag. 1977, 25, 575-581. [CrossRef]

37. Bringi, V.N.; Seliga, T.A. Scattering from Non-Spherical Hydrometeors. In Annales des Télécommunications; Springer: Berlin/Heidelberg, Germany, 1977; Volume 32, pp. 392-397.

38. Aydin, K.; Seliga, T.A.; Bringi, V.N. Differential Radar Scattering Properties of Model Hail and Mixed-Phase Hydrometeors. Radio Sci. 1984, 19, 58-66. [CrossRef]

39. Willis, T.M.; Weil, H. Disk Scattering and Absorption by an Improved Computational Method. Appl. Opt. 1987, 26, 3987-3995. [CrossRef] 
40. Uzunoglu, N.K.; Holt, A.R. Scattering of Electromagnetic-Radiation from Dielectric Scatterers. J. Phys. A-Math. General. 1977, 10, 413-424. [CrossRef]

41. Uzunoglu, N.; Evans, B.G.; Holt, A.R. Evaluation of Scattering of an Electromagnetic-Wave from Precipitation Particles by use of Fredholm Integral-Equations. Electron. Lett. 1976, 12, 312-313. [CrossRef]

42. Goedecke, G.H.; O’Brien, S.G. Scattering by Irregular Inhomogeneous Particles via the digitized Green's Function Algorithm. Appl. Opt. 1988, 27, 2431-2438. [CrossRef]

43. Evans, K.F.; Vivekanandan, J. Multiparameter Radar and Microwave Radiative-Transfer Modeling of Nonspherical Atmospheric Ice Particles. Trans IEEE Geosci. Remote. Sens. 1990, 28, 423-437. [CrossRef]

44. Schneider, T.L.; Stephens, G. Theoretical Aspects of Modelling Backscatter by Cirrus Ice Particles at Millimeter Wavelengths. J. Atmos. Sci. 1995, 52, 4367-4385. [CrossRef]

45. Boerner, W.M. (Ed.) Direct and Inverse Methods in Radar Polarimetry; Part 2; Kluwer Academic: Dordrecht, The Netherland, 1992.

46. Pruppacher, H.R.; Beard, K.V. A Wind Tunnel Investigation of the Internal Circulation Shape of Water Drops Falling at Terminal Velocity in Air. Q. J. R. Meteorol. Soc. 1970, 96, 247-256. [CrossRef]

47. McCormick, G.C.; Hendry, A.; Barge, B.L. The Anisotropy of Precipitation Media. Nature 1972, 238, $214-216$. [CrossRef]

48. Van de Hulst, H.C. Light Scattering by Small Particles; Dover: New York, NY, USA, 1981.

49. Seliga, T.A.; Bringi, V.N. Potential Use of Radar Differential Reflectivity Measurements at Orthogonal Polarizations for Measuring Precipitation. J. Appl. Meteorol. 1976, 15, 69-76. [CrossRef]

50. Vivekanandan, J.; Bringi, V.N.; Raghavan, R. Multiparameter Radar Modeling and Observations of Melting Ice. J. Atmos. Sci. 1990, 47, 549-564. [CrossRef]

51. Humphries, R.G. Observations and Calculations of Depolarization Effects at $3 \mathrm{GHz}$ due to Precipitation. J. Rech. Atmos. 1974, 8, 151-161.

52. Seliga, T.A.; Bringi, V.N. Differential Reflectivity and Differential Phase Shift: Applications in Radar Meteorology. Radio Sci. 1978, 13, 271-275. [CrossRef]

53. Mueller, E.A. Calculation Procedure for Differential Propagation Phase Shift. In Proceedings of the 24th Conference on Radar Meteorology, Tallahassee, FL, USA, 27-31 March 1989; American Meteorological Society: Boston, MA, USA, 1989.

54. Jameson, A.R. Microphysical Interpretation of Multi-Parameter Radar Measurements in Rain. Part I: Interpretation of Polarization Measurements and Estimation of Raindrop Shapes. J. Atmos. Sci. 1983, 40, 1792-1802. [CrossRef]

55. Jameson, A.R. Microphysical Interpretation of Multiparameter Radar Measurements in Rain. Part III: Interpretation and Measurement of Propagation Differential Phase Shift between Orthogonal Linear Polarizations. J. Atmos. Sci. 1985, 42, 607-614. [CrossRef]

56. Jones, D.M.A. The Shape of Raindrops. J. Meteorol. 1959, 16, 504-510. [CrossRef]

57. Bringi, V.N.; Cherry, S.M.; Hall, M.P.M.; Seliga, T.A. A New Accuracy in Determining Rainfall Rates and Attenuation due to Rain by means of Dual-Polarization measurements. In Antennas and Propagation; Institution of Electrical Engineers: Stevenage, Hertford, UK, 1978; pp. 120-124.

58. McCormick, G.C. Relationship of Differential Reflectivity to Correlation in Dual-Polarization Radar. Electron. Lett. 1979, 15, 255-256. [CrossRef]

59. Jameson, A.R.; Davé, J.H. An Interpretation of Circular Polarization Measurements Affected by Propagation Differential Phase Shift. J. Atmos. Ocean. Technol. 1988, 5, 405-415. [CrossRef]

60. Krishnaih, P.R.; Hagis, P. Steinberg. A Note on the Bivariate Chi Distribution. SIAM Rev. 1963, 5, $140-144$. [CrossRef]

61. Middleton, D. An Introduction to Statistical Communication Theory; McGraw-Hill: New York, NY, USA, 1960.

62. Bringi, V.N.; Seliga, T.A.; Cherry, S.M. Statistical Properties of the Dual-Polarization Differential Reflectivity. Trans. IEEE Geosci. Remote Sens. 1983, 21, 215-220. [CrossRef]

63. Atlas, D. Highlights of the Symposium on the Multiple-Parameter Radar Measurements of Precipitation-Personal Reflections. Radio Sci. 1984, 19, 238-242. [CrossRef]

64. Hall, M.P.M. Symposium on Multiple-Parameter Radar Measurements of Precipitation; Rutherford Appleton Laboratory: Bournemouth, UK, 1982.

65. Hall, M.P.M. Foreword to Special Issue on Multiple-Parameter Radar Measurements of Precipitation. Radio Sci. 1984, 19 . 
66. Hall, M.P.M.; Goddard, J.W.F.; Cherry, S.M. Identification of Hydrometeors and other Targets by Dual-Polarization Radar. Radio Sci. 1984, 18, 132-140. [CrossRef]

67. Leitao, M.J.; Watson, P.A. Application of Dual Linearly Polarized Radar Data to Prediction of Microwave Path Attenuation at 10-30 GHz. Radio Sci. 1984, 19, 209-221. [CrossRef]

68. Aydin, K.; Seliga, T.A.; Balaji, V. Remote Sensing of Hail with a Dual-Polarization Radar. J. Clim. Appl. Meteorol. 1986, 25, 1475-1484. [CrossRef]

69. Vivekanandan, J.; Zrnic, D.S.; Ellis, S.M.; Oye, R.; Ryzhkov, A.V.; Straka, J. Cloud Microphysics Retrieval Using S-Band Dual-Polarization Radar Measurements. Bull. Am. Meteorol. Soc. 1999, 80, 381-388. [CrossRef]

70. Liu, H.; Chandrasekar, V. Classification of Hydrometeors Based on Polarimetric Radar Measurements: Development of Fuzzy Logic and Neuro-Fuzzy Systems, and in situ Verification. J. Atmos. Ocean. Technol. 1999, 17, 140-164. [CrossRef]

71. Straka, J.M.; Zrnić, D.S.; Ryzhkov, A.V. Bulk Hydrometeor Classification and Quantification Using Polarimetric Radar Data: Synthesis of Relations. J. Appl. Meteorol. 2000, 39, 1341-1372. [CrossRef]

72. Bringi, V.N.; Seliga, T.A.; Cooper, W.A. Analysis of Aircraft Hydrometeor Spectra and Differential Reflectivity (ZDR) Radar Measurements during the Cooperative Convective Precipitation Experiment. Radio Sci. 1984, 19, 157-167. [CrossRef]

73. Green, A.W. An Approximation for the Shape of Large Raindrops. J. Appl. Meteorol. 1975, 14, $1578-1583$. [CrossRef]

74. Szakáll, M.; Diehl, K.; Mitra, S.K.; Borrmann, S. A Wind Tunnel Study on the Shape, Oscillation, and Internal Circulation of Large Raindrops with Sizes between 2.5 and 7.5 mm. J. Atmos. Sci. 2009, 66, 755-765. [CrossRef]

75. Thurai, M.; Bringi, V.N.; Szakáll, M.; Mitra, S.K.; Beard, K.V.; Borrmann, S. Drop Shapes and Axis Ratio Distributions: Comparison between 2D Video Disdrometer and Wind-Tunnel Measurements. J. Atmos. Ocean. Technol. 2009, 26, 1427-1432. [CrossRef]

76. Beard, K.V.; Chuang, C. A New Model for the Equilibrium Shape of Raindrops. J. Atmos. Sci. 1987, 44, 1509-1524. [CrossRef]

77. Brandes, E.A.; Zhang, G.; Vivekanandan, J. Experiments in Rainfall Estimation with a Polarimetric Radar in a Subtropical Environment. J. Appl. Meteorol. 2002, 41, 674-685. [CrossRef]

78. Bader, M.J.; Clough, S.A.; Cox, G.P. Aircraft and Dual Polarization Radar Observations of Hydrometeors in Light Stratiform Precipitation. Q. J. R. Meteorol. Soc. 1987, 103, 269-280. [CrossRef]

79. Illingworth, A.J.; Goddard, J.W.F.; Cherry, S.M. Polarization Radar Studies of Precipitation in Convective Storms. Q. J. R. Meteorol. Soc. 1987, 113, 469-489. [CrossRef]

80. Johnson, D.B. The Role of Giant and Ultragiant Aerosol Particles in Warm Rain Initiation. J. Atmos. Sci. 1982, 39, 448-460. [CrossRef]

81. Caylor, I.J.; Illingworth, A.J. Radar Observations and Modeling of Warm Rain Initiation. Q. J. R. Meteorol. Soc. 1987, 113, 1171-1191. [CrossRef]

82. Caylor, I.J.; Goddard, J.W.F.; Hoppper, S.E.; Illingworth, A.J. Bright Band Errors in Radar Estimates of Rainfall: Identification and Correction using Polarization Diversity. In International Weather Radar Networking; Collier, C.G., Ed.; Springer: Berlin/Heidelberg, Germany, 1989; pp. 295-304.

83. Goddard, J.W.F.; Eastment, J.D.; Thurai, M. The Chilbolton Advanced Meteorological Radar-A Tool for Multidisciplinary Atmospheric Research. J. Electron. Commun. Eng. 1994, 6, 77-86. [CrossRef]

84. Herzegh, P.H.; Carbone, R.E. The Influence of Antenna Illumination Function Characteristic on Differential Reflectivity Measurements. In Proceedings of the 22nd Radar Meteorology Conference, Zurich, Switzerland, 10-13 September 1984; American Meteorological Society: Boston, MA, USA, 1984; pp. 281-286.

85. Pointin, Y.; Ramond, D.; Fournet-Fayard, J. Radar Differential Reflectivity $Z_{\mathrm{DR}}$ : A Real-Case Evaluation of Errors Induced by Antenna Characteristics. J. Atmos. Ocean. Technol. 1988, 5, 416-423. [CrossRef]

86. Chandrasekar, V.; Keeler, R.J. Antenna Pattern Analysis and Measurements for Multiparameter Radars. J. Atmos. Ocean. Technol. 1993, 10, 674-683. [CrossRef]

87. Bringi, V.N.; Seliga, T.A.; Aydin, K. Hail Detection with a Differential Reflectivity Radar. Science 1984, 225, 1145-1147. [CrossRef] [PubMed]

88. Bringi, V.N.; Rasmussen, R.M.; Vivekanandan, J. Multiparameter Radar Measurements in Colorado Convective Storms. Part I: Graupel Melting Studies. J. Atmos. Sci. 1986, 43, 2545-2563. [CrossRef] 
89. Bringi, V.N.; Vivekanandan, J.; Tuttle, J.D. Multiparameter Radar Measurements in Colorado Convective Storms. Part II: Hail Detection Studies. J. Atmos. Sci. 1986, 43, 2564-2577. [CrossRef]

90. Rasmussen, R.M.; Levizzani, V.; Pruppacher, H.R. A Wind Tunnel and Theoretical Study on the Melting Behavior of Atmospheric Ice Particles: III. Experiment and Theory for Spherical Ice Particles of Radius $>500 \mu \mathrm{m}$. J. Atmos. Sci. 1984, 41, 381-388. [CrossRef]

91. Chandrasekar, V.; Bringi, V.N.; Brockwell, P. Statistical Properties of Dual-Polarized Radar Signals. In Proceedings of the 23rd Radar Meteorology and Cloud Physics Conference, Snowmass, CO, USA, 22-26 September 1986; American Meteorological Society: Boston, MA, USA, 1986.

92. Scarchilli, G.; Goroucci, E.; Chandrasekar, V.; Seliga, T.A. Rainfall Estimation Using Polarimetric Techniques at C-Band Frequencies. J. Appl. Meteorol. 1993, 32, 1150-1160. [CrossRef]

93. Chandrasekar, V.; Bringi, V.N. Simulation of Radar Reflectivity and Surface Measurements of Rainfall. J. Atmos. Ocean. Technol. 1987, 4, 464-478. [CrossRef]

94. Chandrasekar, V.; Bringi, V.N. Error Structure of Multiparameter Radar and Surface Measurements of Rainfall Part I: Differential Reflectivity. J. Atmos. Ocean. Technol. 1988, 5, 783-795. [CrossRef]

95. Chandrasekar, V.; Bringi, V.N. Error Structure of Multiparameter Radar and Surface Measurements of Rainfall Part II: X-Band Attenuation. J. Atmos. Ocean. Technol. 1988, 5, 796-802. [CrossRef]

96. Chandrasekar, V.; Bringi, V.N.; Balakrishnan, N.; Zrnić, D. Error Structure of Multiparameter Radar and Surface Measurements of Rainfall. Part III: Specific Differential Phase. J. Atmos. Ocean. Technol. 1990, 7, 621-629. [CrossRef]

97. Wakimoto, R.M.; Bringi, V.N. Dual-Polarization observations of Microbursts Associated with Intense Convection: The 20 July Storm during the MIST Project. Mon. Weather Rev. 1988, 116, 1521-1539. [CrossRef]

98. Tuttle, J.D.; Bringi, V.N.; Orville, H.D.; Kopp, F.J. Multiparameter Radar Study of a Microburst: Comparison with Model Results. J. Atmos. Sci. 1989, 46, 601-620. [CrossRef]

99. Seliga, T.A.; Humphries, R.G.; Metcalf, J.I. Polarization Diversity in Radar Meteorology: Early Developments. In Radar in Meteorology; Atlas, D., Ed.; American Meteorological Society: Boston, MA, USA, 1990; pp. 153-190.

100. Bringi, V.N.; Hendry, A. Technology of Polarization Diversity Radars for Meteorology. In Radar in Meteorology; Atlas, D., Ed.; American Meteorological Society: Boston, MA, USA, 1990; pp. 153-190.

101. Herzegh, P.H.; Jameson, A.R. Observing Precipitation through Dual-Polarization Radar Measurements. Bull. Am. Meteorol. Soc. 1992, 73, 1365-1376. [CrossRef]

102. Bringi, V.N.; Knupp, K.; Detwiler, A.; Liu, L.; Caylor, I.J.; Black, R.A. Evolution of a Florida Thunderstorm during the Convection and Precipitation/Electrification Experiment: The Case of 9 August 1991. Mon. Weather Rev. 1997, 125, 2131-2160. [CrossRef]

103. Jameson, A.R.; Murphy, M.J.; Krider, E.P. Multiple-Parameter Radar Observations of Isolated Florida Thunderstorms during the Onset of Electrification. J. Appl. Meteorol. 1996, 35, 343-354. [CrossRef]

104. Illingworth, A.J.; Zrnic, D. Workshop on Weather Radar Polarimetry for Research and Operational Applications. Bull. Am. Meteorol. Soc. 1995, 76, 555-558. [CrossRef]

105. Hubbert, J.; Bringi, V.N.; Carey, L.D.; Bolen, S. CSU-CHILL Polarimetric Radar Measurements from a Severe Hail Storm in Eastern Colorado. J. Appl. Meteorol. 1998, 37, 749-775. [CrossRef]

106. Carey, L.D.; Rutledge, S.A. A Multiparameter Radar Case Study of the Microphysical and Kinematic Evolution of a Lightning Producing Storm. Meteorol. Atmos. Phys. 1996, 59, 33-64. [CrossRef]

107. Carter, J.K.; Sirmans, D.; Schmidt, J. Engineering Description of the NSSL dual linear Polarization Doppler Weather Radar. In Proceedings of the 23rd Radar Meteorology and Cloud Physics Conference, Snowmass, CO, USA, 22-26 September 1986; American Meteorological Society: Boston, MA, USA, 1986.

108. Sachidananda, M.; Zrnic, D.S. ZDR Measurement Considerations for a Fast Scan Capability Radar. Radio Sci. 1985, 20, 907-922. [CrossRef]

109. Sachidananda, M.; Zrnic, D.S. Differential Propagation phase-shift and rainfall rate estimation. Radio Sci. 1986, 21, 235-247. [CrossRef]

110. Rummler, W.D. Introduction of a New Estimator for Velocity Spectral Parameters; Technical Memo, MM-68-4121-5; Bell Telephone Laboratories: Whippany, NJ, USA, 1968.

111. Rummler, W.D. Two Pulse Spectral Measurements; Technical Memo, MM-68-4121-15; Bell Telephone Laboratories: Whippany, NJ, USA, 1968.

112. Berger, R.A.; Groginsky, H.L. Estimation of Spectral Moments of Pulse Trains; IEEE: Piscataway, NJ, USA, 1973. 
113. Zrnic, D.S. Spectral Moment Estimation from Correlated Pulse Pairs. IEEE Trans. Aerosp. Electron. Syst. 1977, 4, 344-354. [CrossRef]

114. Sachidananda, M.; Zrnic, D.S. Characteristics of Echoes from Alternately Polarized Transmission; Cooperative Institute for Mesoscale Meteorological Studies (CIMMS) Report No.71; CIMMS: Norman, OK, USA, 1986. Available online: https://nssl.noaa.gov/publications/wsr88d_reports/Characteristics\%20of\%20Echoes\% 20from\%20Alternately\%20Polarized\%20Transmission.pdf (accessed on 30 September 2019).

115. Sachidananda, M.; Zrnić, D.S. Efficient Processing of Alternately Polarized Radar Signals. J. Atmos. Ocean. Technol. 1989, 6, 173-181. [CrossRef]

116. Balakrishnan, N.; Zrnic, D.S. Correction of Propagation Effects at Attenuating Wavelengths in Polarimetric Radars. In Proceedings of the 24th Conference on Radar Meteorology, Tallahassee, FL, USA, 27-31 March 1989; American Meteorological Society: Boston, MA, USA, 1989; pp. 287-291.

117. Bringi, V.N.; Chandrasekar, V.; Balakrishnan, N.; Zrnić, D. An Examination of Propagation Effects in Rainfall on Radar Measurements at Microwave Frequencies. J. Atmos. Ocean. Technol. 1990, 7, 829-840. [CrossRef]

118. Balakrishnan, N.; Zrnić, D.S. Estimation of Rain and Hail Rates in Mixed-Phase Precipitation. J. Atmos. Sci. 1990, 47, 565-583. [CrossRef]

119. Balakrishnan, N.; Zrnic, D.S. Use of Polarization to Characterize Precipitation and Discriminate Large Hail. J. Atmos. Sci. 1990, 47, 1525-1540. [CrossRef]

120. Zrnic, D.S.; Balakrishnan, N.; Ziegler, C.L.; Bringi, V.N.; Aydin, K.; Matejka, T. Polarimetric Signatures in the Stratiform Region of a Mesoscale Convective System. J. Appl. Meteorol. 1993, 32, 678-693. [CrossRef]

121. Liu, L.; Bringi, V.N.; Chandrasekar, V.; Mueller, E.A.; Mudukutore, A. Analysis of the Copolar Correlation Coefficient between Horizontal and Vertical Polarizations. J. Atmos. Ocean. Technol. 1994, 11, 950-963. [CrossRef]

122. Zrnić, D.S.; Bringi, V.N.; Balakrishnan, N.; Aydin, K.; Chandrasekar, V.; Hubbert, J. Polarimetric Measurements in a Severe Hailstorm. Mon. Weather Rev. 1993, 121, 2223-2238. [CrossRef]

123. Doviak, R.J.; Zrnic, D.S. Doppler Radar and Weather Observations, 2nd ed.; Academic Press: San Diego, CA, USA, 1993.

124. Zahrai, A.; Zrnić, D.S. The 10-cm-Wavelength Polarimetric Weather Radar at NOAA's National Severe Storms Laboratory. J. Atmos. Ocean. Technol. 1993, 10, 649-662. [CrossRef]

125. Ryzhkov, A.V.; Zrnić, D.S. Precipitation Observed in Oklahoma Mesoscale Convective Systems with a Polarimetric Radar. J. Appl. Meteorol. 1994, 33, 455-464. [CrossRef]

126. Zrnić, D.S. Complete Polarimetric and Doppler Measurements with a Single Receiver Radar. J. Atmos. Ocean. Technol. 1991, 8, 159-165. [CrossRef]

127. Cordesses, J.; Foumet-Fayard, R.; Ramond, D.; Amayenc, P. ANATOL: A S-band Differential Reflectivity Radar for Meteorological Studies. In Proceedings of the 21st Conference on Radar Meteorology, Edmonton, AB, Canada, 19-23 September 1983; American Meteorological Society: Boston, MA, USA, 1983.

128. Husson, D.; Pointin, Y. Quantitative estimation of the hail fall intensity with a dual polarisation radar and a hailpad network. In Proceedings of the 24th Conference on Radar Meteorology, Tallahassee, FL, USA, 27-31 March 1989; American Meteorological Society: Boston, MA, USA, 1989; pp. 318-321.

129. Ryzhkov, A.V.; Zhuravlyov, V.B.; Rybakova, N.A. Preliminary Results of X-Band Polarization Radar Studies of Clouds and Precipitation. J. Atmos. Ocean. Technol. 1994, 11, 132-139. [CrossRef]

130. Leonardi, R.M.; Scarchilli, G.; Gorgucci, E. Polar C55: A C-band advanced meteorological radar developed for C.N.R. Italy. In Proceedings of the 22nd Radar Meteorology Conference, Zurich, Switzerland, 10-13 September 1984; American Meteorological Society: Boston, MA, USA, 1984; pp. 238-243.

131. Schroth, A.C.; Chandra, M.S.; Mesichner, P.F. A C-Band Coherent Polarimetric Radar for Propagation and Cloud Physics Research. J. Atmos. Ocean. Technol. 1988, 5, 803-822. [CrossRef]

132. Hubbert, J.; Chandrasekar, V.; Bringi, V.N.; Meischner, P. Processing and Interpretation of Coherent Dual-Polarized Radar Measurements. J. Atmos. Ocean. Technol. 1993, 10, 155-164. [CrossRef]

133. Meischner, P.F.; Bringi, V.N.; Heimann, D.; Höller, H. A Squall Line in Southern Germany: Kinematics and Precipitation Formation as Deduced by Advanced Polarimetric and Doppler Radar Measurements. Mon. Weather Rev. 1991, 119, 678-701. [CrossRef] 
134. Zhang, G.; Mahale, V.; Putnam, B.J.; Qi, Y.; Cao, Q.; Byrd, A.D.; Bukovcic, P.; Zrnic, D.S.; Gao, J.; Xue, M. Current Status and Future Challenges of Weather Radar Polarimetry: Bridging the Gap between Radar Meteorology/Hydrology/Engineering and Numerical Weather Prediction. Adv. Atmos. Sci. 2019, 36, 571-588. [CrossRef]

135. Morrison, H.; Milbrandt, J.A. Parameterization of Cloud Microphysics Based on the Prediction of Bulk Ice Particle Properties. Part I: Scheme Description and Idealized Tests. J. Atmos. Sci. 2015, 72, $287-311$. [CrossRef]

136. Cholette, M.; Morrison, H.; Milbrandt, J.A.; Thériault, J.M. Parameterization of the Bulk Liquid Fraction on Mixed-Phase Particles in the Predicted Particle Properties (P3) Scheme: Description and Idealized Simulations. J. Atmos. Sci. 2019, 76, 561-582. [CrossRef]

137. Harrington, J.Y.; Sulia, K.; Morrison, H. A Method for Adaptive Habit Prediction in Bulk Microphysical Models. Part I: Theoretical Development. J. Atmos. Sci. 2013, 70, 349-364. [CrossRef]

138. Brdar, S.; Seifert, A. McSnow: A Monte-Carlo Particle Model for Riming and Aggregation of Ice Particles in a Multidimensional Microphysical Phase Space. J. Adv. Model. Earth Sys. 2018, 10, 187-206. [CrossRef]

139. Grabowski, W.W.; Morrison, H.; Shima, S.; Abade, G.C.; Dziekan, P.; Pawlowska, H. Modeling of Cloud Microphysics: Can We Do Better? Bull. Am. Meteorol. Soc. 2019, 100, 655-672. [CrossRef]

140. Rauber, R.M.; Nesbitt, S.W. Radar Meteorology: A First Course; John Wiley and Sons: Hoboken, NJ, USA, 2018. 141. Zhang, G. Weather Radar Polarimetry; CRC Press: Boca Raton, FL, USA, 2017.

(C) 2019 by the authors. Licensee MDPI, Basel, Switzerland. This article is an open access article distributed under the terms and conditions of the Creative Commons Attribution (CC BY) license (http://creativecommons.org/licenses/by/4.0/). 